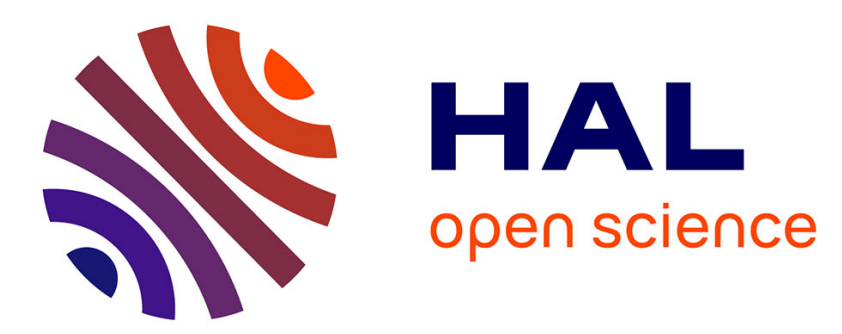

\title{
Striatal cholinergic interneurons regulate cognitive and affective dysfunction in partially dopamine-depleted mice
}

Samira Ztaou, Juliette Lhost, Isabelle Watabe, Giulia Giulia Torromino, Marianne Amalric

\section{To cite this version:}

Samira Ztaou, Juliette Lhost, Isabelle Watabe, Giulia Giulia Torromino, Marianne Amalric. Striatal cholinergic interneurons regulate cognitive and affective dysfunction in partially dopamine-depleted mice. European Journal of Neuroscience, 2018, 48 (9), pp.2988-3004. 10.1111/ejn.14153 . hal01974268

\section{HAL Id: hal-01974268 \\ https://hal.science/hal-01974268}

Submitted on 8 Jan 2019

HAL is a multi-disciplinary open access archive for the deposit and dissemination of scientific research documents, whether they are published or not. The documents may come from teaching and research institutions in France or abroad, or from public or private research centers.
L'archive ouverte pluridisciplinaire HAL, est destinée au dépôt et à la diffusion de documents scientifiques de niveau recherche, publiés ou non, émanant des établissements d'enseignement et de recherche français ou étrangers, des laboratoires publics ou privés. 
Journal section: Clinical and Translational Neuroscience \& Neurosystems

\title{
Striatal cholinergic interneurons regulates cognitive and affective dysfunction in partially dopamine depleted mice
}

Samira Ztaou ${ }^{1 \#}$, Juliette Lhost $^{1}$, Isabelle Watabe ${ }^{2}$, Giulia Torromino ${ }^{1,3}$, Marianne Amalric ${ }^{1 \S}$

\author{
${ }^{1}$ Aix Marseille Univ, CNRS, LNC, FR3C, Marseille, France \\ ${ }^{2}$ Aix Marseille Univ, CNRS, LNIA, FR3C, Marseille, France \\ ${ }^{3}$ Department of Biology and Biotechnology Charles Darwin, Sapienza University of Rome, Italy
}

${ }^{\#}$ Author is now affiliated to:

Department of Molecular Therapeutics, New York State Psychiatric Institute

Department of Psychiatry, Columbia University, New York, NY 10032, USA

${ }^{\S}$ Correspondence should be addressed to Marianne AMALRIC:

Aix-Marseille University, CNRS, UMR 7291, Laboratoire de Neurosciences Cognitives (LNC), FR3C 3512, Case C, 3, place Victor Hugo, 13331 Marseille cedex 03, France

Tel: +33 (0) 4135509 35; Fax: +33 (0) 413550958

E-mail: marianne.amalric@univ-amu.fr

Running title: Striatal cholinergic interneurons and non-motor parkinsonian symptoms

Keywords: Parkinson's disease, non-motor symptoms, muscarinic M1 receptor subtypes, striatum

Total number of pages (41), figures (4), table (1)

Total number of words in: the whole manuscript (8712), the abstract (223) 


\begin{abstract}
Early non-motor symptoms such as mood disorders and cognitive deficits are increasingly recognized in Parkinson's disease (PD). They may precede the characteristic motor symptomatology caused by dopamine (DA) neuronal loss in the substantia nigra pars compacta (SNc). It is well-known that striatal cholinergic interneurons (ChIs) are emerging as key regulators of PD motor symptom, however, their involvement in the cognitive and affective alterations occurring in the premotor phase of PD is poorly understood. We used optogenetic photoinhibition of striatal ChIs in mice with mild nigrostriatal 6-hydroxydopamine (6-OHDA) lesions and assessed their role in anxiety-like behavior in the elevated plus maze, social memory recognition of a congener and visuospatial object recognition. In transgenic mice specifically expressing halorhodopsin (eNpHR) in cholinergic neurons, striatal ChIs photoinhibition reduced the anxiety-like behaviour and reversed social and spatial short-term memory impairment induced by moderate DA depletion (e.g. 50\% loss of tyrosine hydroxylase TH-positive neurons in the SNc). Systemic injection of telenzepine $(0.3 \mathrm{mg} / \mathrm{kg})$, a preferential M1 muscarinic cholinergic receptors antagonist, improved anxiety-like behaviour, social memory recognition but not spatial memory deficits. Our results suggest that dysfunction of the striatal cholinergic system may play a role in the short-term cognitive and emotional deficits of partially DA-depleted mice. Blocking cholinergic activity with M1 muscarinic receptor antagonists may represent a possible therapeutic target, although not exclusive, to modulate these early non-motor deficits.
\end{abstract}




\section{Introduction}

Although Parkinson's disease (PD) has traditionally been viewed as a motor disorder, caused by the progressive loss of dopaminergic (DA) neurons in the substantia nigra pars compacta (SNc) (Obeso et al., 2000), other symptoms predate for many years the appearance of motor ones including depression, anxiety, mood fluctuations, sleep behavior disorder, olfactory deficit and cognitive impairment (Chaudhuri et al., 2006; Chaudhuri \& Odin, 2010; Chaudhuri et al., 2011). These non-motor symptoms in PD represent one of the major challenge faced in the management of PD because it is underdiagnosed and do not respond to DA therapy. Animal models represent a useful tool to better understand disease mechanisms and can be used to test new therapeutic intervention. Recently, a number of preclinical studies have reported anxietylike responses and mild cognitive impairments in rodent models of prodromal phase of PD produced by low doses of DA neurotoxins (Magen \& Chesselet, 2010; Lelos \& Dunnett, 2011). While DA depletion is the primary cause of motor impairment, the neural substrates underlying the neuropsychiatric and cognitive deficits associated with PD are the subjects of increasing research. The appearance of non-motor symptoms of PD may result from the loss of noradrenergic, serotoninergic as well as cholinergic neurons, followed by rearrangement of neuronal networks in limbic structures such as the amygdala, hippocampus and prefrontal cortex (Scatton et al., 1983; Remy et al., 2005; Kish et al., 2008; Bohnen \& Albin, 2011; O’Callaghan \& Lewis 2017). Dysfunction of cholinergic neurotransmission in the cortex and the basal ganglia may occur at early stages of PD consecutive to the neurodegeneration of cholinergic neurons in the nucleus basalis of Meynert (Braak et al., 2003) and/or the pedunculopontine nucleus (PPN) (Hirsch et al., 1987; Jellinger, 1988; Pahapill \& Lozano, 2000; Karachi et al., 2010). The PPN and lateral tegmental nuclei also provide cholinergic inputs to the striatum (Dautan et al., 2014) that may affect striatal cholinergic signaling. Nevertheless, striatal cholinergic interneurons (ChIs) are the primary internal source for 
acetylcholine (ACh), the highest level of ACh in the brain. In animal models of PD, striatal ChIs activity is modulated by rewarding and aversive stimuli and play an important role in attentional, in learning and memory or conditioning of response to these stimuli (Goldberg \& Reynolds, 2011; Bradfield et al., 2013; Lenz \& Lobo, 2013; Lim et al., 2014; Apicella, 2017). It was recently showed that alteration of ChIs synaptic plasticity, in rats overexpressing truncated human $\alpha$-synuclein in the SNc, is associated with early cognitive deficits (Tozzi et al. 2016). We therefore questioned whether striatal ChIs could also contribute to cognitive and anxiety symptoms in a partial 6-OHDA mice model of early PD, when motor symptoms are not manifest.

Despite their low number in the striatum (1-2\%), ChIs are regarded as key regulators of basal ganglia function in normal and diseased states (Pisani et al., 2007; Lester et al., 2010; Bonsi et al., 2011; Threlfell \& Cragg, 2011; Brichta et al., 2013; Scarr, 2013). Their effects are mediated by muscarinic and nicotinic receptors signaling. Muscarinic receptors (M1-M5, mAChRs) are highly expressed within the striatum, particularly the M1 subtypes that are primarily expressed on medium spiny neurons (MSNs) (Zhou et al., 2003; Kreitzer, 2009). The discovery of drugs acting on specific mAChR subtypes raised renewed interest in the modulation of striatal cholinergic signaling to alleviate basal ganglia disorders (Wess et al., 2007; Michelle Lewis et al., 2008; Eskow Jaunarajs et al., 2015; Shen et al., 2015). The imbalance between ACh and DA activity in the striatum is classically considered as central to the development of motor symptoms of PD (Di Chiara et al., 1994; Pisani et al., 2007), although the two systems may also act in conjunction (Threlfell et al., 2012; Calabresi et al. 2014; Parker et al., 2016). Whether the activity of the striatal cholinergic system is also affected by a mild nigrostriatal DA denervation is largely unknown.

Here, we provide evidence that partial striatal DA depletion impairs emotional and cognitive processes in mice without affecting motor activity. Optogenetic inhibition of striatal ChIs 
reverses these premotor symptoms. Muscarinic M1 ACh receptors appear to be involved in this effect as the selective M1 receptor antagonist telenzepine has anxiolytic properties, restores social but not visuospatial memory. These results underline the importance of ChIs in the control of cognitive and neuropsychiatric symptoms in rodent models of PD.

\section{Materials and Methods}

\section{Mice}

All procedures were approved by the French National Ethical Committee (authorization no. 00196.01) and in accordance with the recommendations of the EEC (2010/63/UE) for care and use of laboratory animals. All animals were housed in groups of 4-5 with rodent chow and water ad libitum in a temperature-controlled room $\left(21^{\circ} \mathrm{C}\right)$ on a $12: 12 \mathrm{~h}$ dark-light cycle (lights on at 07:00).

Optogenetic. Choline acetyltransferase ChAT-IRES-Cre knock-in mice (ChAT ${ }^{\text {cre/cre }}$ mice, stock number: 006410) and LoxP-stop-eNpHR3.0-EYFP mice (Ai39 mice, stock number: 014539) were purchased from Jackson Laboratory (Bar Arbor, ME). Ai39 mice were crossed with $\mathrm{ChAT}^{\mathrm{cre} / \mathrm{cre}}$ mice to induce eNpHR3.0 expression in cholinergic neurons $\left(\mathrm{Rosa}^{\mathrm{eNpHR} /+}: \mathrm{ChAT}^{\mathrm{cre} /+}\right.$ mice, here called 'eNpHR transgenic mice'). Pharmacology. Wild type C57BL/6 male mice aged 8 weeks were purchased from Charles River Laboratories (L'Arbresle, France).

\section{Stereotaxic surgery}

Mice were deeply anaesthetized with intraperitoneal (i.p.) injections of ketamine and xylazine (100 and $10 \mathrm{mg} / \mathrm{kg}$, respectively) in a volume of $10 \mathrm{ml} / \mathrm{kg}$ and placed on heated pad into a stereotaxic apparatus (David Kopf Instruments).

Nigrostriatal dopaminergic lesions. eNpHR transgenic mice and C57BL/6 mice received bilateral microinjections into the striatum of low doses of 6-hydroxydopamine hydrobromide 
(6-OHDA, Tocris Bioscience, UK) calculated at a free-base concentration of $4 \mu \mathrm{g} / \mu \mathrm{l}$. A solution of $1 \mu \mathrm{l} /$ side of 6-OHDA (diluted in $0.9 \%$ sterile $\mathrm{NaCl}$ containing $0.02 \%$ ascorbic acid to prevent oxidation) or vehicle $(0.9 \% \mathrm{NaCl}$ in $0.02 \%$ ascorbic acid) was slowly injected into the dorsal striatum at the following coordinates: $+1.0 \mathrm{~mm} \mathrm{AP}, \pm 1.5 \mathrm{~mm} \mathrm{ML},-3.2 \mathrm{~mm} \mathrm{DV}$, according to the atlas of Paxinos and Franklin (2001). Stereotaxic microinjections were made with a $10 \mu$ Hamilton microsyringe, connected to an injection cannula (33 gauge, Plastics One, Roanoke, VA) by a polyethylene tubing (Tygon catheter; $0.25 \mathrm{~mm}$, i.d.) and controlled by an injection pump (CMA/100; CMA/Microdialysis, Stockholm, Sweden) at a flow rate of 0.3 $\mu \mathrm{l} / \mathrm{min}$. At the end of injection, injector needles remained in place for 3 more min to allow for diffusion of the solution before being slowly retracted.

Optic fiber implantation. For optogenetic experiments, eNpHR mice submitted to 6-OHDA procedure were also implanted with optical fibers during the same surgery. Optical fibers consisted of a zirconia ferrule with a $200 \mu \mathrm{m}$ diameter and $3.0 \mathrm{~mm}$ long cleaved bare optic fibers (0.22 numerical aperture (Doric Lenses, Quebec, Canada). Fibers were bilaterally implanted into the striatum at the following coordinates: $+0,5 \mathrm{~mm} \mathrm{AP}, \pm 1.5 \mathrm{~mm} \mathrm{ML},-2.8 \mathrm{~mm}$ DV (Paxinos \& Franklin, 2001) and affixed to the skull with superbond glue and dental cement. All mice were given $0.06 \mathrm{ml}$ of rimadyl 1/10, $0.02 \mathrm{ml}$ baytril $1 / 10$ and glucose $5 \% 0.3 \mathrm{ml}$ after surgery to prevent infections and help alleviate pain associated with the surgical procedure. Mice were monitored daily and received glucose injections and wet laboratory chow to avoid dehydration if needed. All experiments were performed after a minimum of 10 to 14 days period of recovery after surgery.

\section{Optogenetic photoinhibition}

For bilateral illumination, optical fibers were connected to the laser through a rotary joint (FRJ_1x2i_FC-2FC, Doric Lenses) that sent half of the light coming from the laser into each 
of the two optical fibers inserted in the mouse brain and enabled the mouse to move freely during behavioral assessments. Light was provided by a yellow laser $(589 \mathrm{~nm}, 75.2 \mathrm{~mW}$, continuous stimulation) (Combined Dual Wavelength DPSS Laser System, Laserglow, Canada). Optical-fiber light power was measured using a power meter (PM100D, ThorLabs) connected to a photodiode power sensor (S120C, 400-1100 nm, $50 \mathrm{~mW}$, ThorLabs) and verified before and after every behavioral experiments. The intensity was calculated using the model based on direct measurements in mammalian brain tissue for predicting irradiance values developed in K. Deisseroth's laboratory and available at the webpage http://www.stanford.edu/group/dlab/cgi-bin/graph/chart.php. Light intensity at $0.2 \mathrm{~mm}$ from fiber tip was calculated to be $20 \mathrm{~mW} / \mathrm{mm}^{2}$ (corresponding to $140 \mathrm{~mW} / \mathrm{mm}^{2}$ at the fiber tip).

\section{Drug treatment}

Telenzepine dihydrochloride hydrate was purchased from Sigma-Aldrich (St-Quentin Fallavier, France). Telenzepine $(0.3 \mathrm{mg} / \mathrm{kg})$ was dissolved with $0.9 \%$ sterile $\mathrm{NaCl}$ and administered intraperitoneally (i.p.) in a volume of $10 \mathrm{ml} / \mathrm{kg}, 30 \mathrm{~min}$ before behavioral tests to cover the period of maximal drug effect (Aliane et al., 2011; Francardo et al., 2011).

\section{Behavioral tests}

A battery of tests assessing cognitive and emotional impairment was performed after surgery in the different groups. All behavioral testing was carried out in dim light (8-12 Lux) during the light cycle. Sessions were recorded and analysed using a video-tracking software (Viewpoint Life Sciences, Lyon, France). Scoring was done off-line by an investigator blind to the treatment. For each experiment, locomotor activity was measured by the total distance covered in the apparatus (open field or maze) during the testing period. A mouse that spends an inordinate amount of time (at least $50 \%$ of the 5-min test period) vigorously grooming was 
excluded from data analysis. Equipment was cleaned with a damp cloth between mouse trials.

Elevated plus maze (EPM). The elevated plus maze was performed to assess anxiety-related behavior. The elevated plus maze consisted of two open and two enclosed horizontal perpendicular arms (6 cm wide, $37 \mathrm{~cm}$ long) with $18 \mathrm{~cm}$-high black plastic walls for the enclosed arms, which were elevated $50 \mathrm{~cm}$ above the floor. Light intensity was 12 Lux in open arms and 4 Lux in closed arms. Each mouse was placed in the central area of the plus maze $(6 \mathrm{x}$ $6 \mathrm{~cm}$ ), facing an open arm. From a 5-min exploration period, the paths of the animals, distance traveled (in $\mathrm{cm}$ ), number of entries and time spent in each of the three compartments (open and closed arms, center area) were videotracked (Viewpoint) and quantified. The propensity to avoid the open arms is considered as an index of anxiety (Lister, 1987). Results are expressed as a percent of time spent and distance traveled in the open arms relative to the total amount of time and distance spent in the entire maze. The number of entries in open arms as a percent of total arm entries was also quantified.

Social interaction (SI). Short-term social memory was evaluated with the social interaction test (Kalkonde et al., 2011). Adult mice were habituated for $30 \mathrm{~min}$ to the testing room prior to the beginning of the experiment. Adult mice were then allowed to habituate for $10 \mathrm{~min}$ to an open field arena $(50 \times 50 \mathrm{~cm}$ with a $30 \mathrm{~cm}$-high white plastic wall) containing a small cage with stainless steel railings $(8 \times 8 \times 10 \mathrm{~cm}$-high $)$ in its center. After placing the juvenile $(18-21$ days old) in the small cage, the time and the number of adult-initiated contacts with the juvenile were recorded for $4 \mathrm{~min}$. At the end of the first presentation (P1), the adult mice was removed from the open field, kept in an individual cage for a 30 min-delay period and then re-exposed to the same juvenile for 4 min (second presentation, P2). Mice re-exposed to the same juvenile 30 min after an initial exposure display a little investigatory behavior, reflecting an active recognition (Kalkonde et al., 2011). Minimum exploration time of juvenile during P1 was set to $5 \mathrm{~s}$, and mice that did not reach this criterion were excluded from data analysis. Data are 
expressed as a ratio of the duration of contacts (in sec) and number of contacts toward the same juvenile during P2 to P1.

Object recognition $(\mathrm{RO})$. Spatial memory and non-spatial novelty memory were assessed according to the object recognition test previously described (Beer et al., 2014). On the first day, mice were habituated to an open field arena $(50 \times 50 \mathrm{~cm}$ with a $30 \mathrm{~cm}$-high white plastic wall) surrounded by a distal cue (double red stripe), for $30 \mathrm{~min}$. The following day, mice were tested for their reaction to spatial or non-spatial memory of objects. The test procedure included an acquisition phase (10 $\mathrm{min})$, a 30-min delay period where mice returned to their home cages, and a recognition phase (10 min). During the acquisition phase, animals were exposed to two identical objects (falcon tissue culture flask filled with sand) placed in the northwest (NW) (object $\mathrm{A}$ ) and northeast (NE) (object B) corner of the open field. In the spatial memory test (SRO), in the recognition phase, object A was placed at the same location (NW) while object B was placed at a different location (southeast SE) than experienced during the acquisition phase. In the non-spatial novelty test (NSRO), the two objects were placed at the exact same positions than in the acquisition phase, while object A was identical to that tested in the acquisition phase and placed in the NW corner, object B (plastic tower) was novel and placed in the NE corner. Active recognition was assessed by using the natural preference of rodents for novel object compared to familiar object. Accordingly, mice that successfully recognized one familiar item (e.g. previously experienced during the acquisition phase) should spend more time exploring the novel item than the familiar one. Spatial test and non-spatial novelty test were counterbalanced across animals and conditions. After each trial, the open field and objects were cleaned with a $10 \%$ ethanol solution. Minimum exploration time of objects A and B during the acquisition phase ( $T_{1} A$ and $T_{1} B$, respectively) was set to $2 \mathrm{~s}$, and mice that did not reach this criterion were excluded from data analysis. The time spent exploring each object during the recognition phase $\left(T_{2} A\right.$ and $T_{2} B$, respectively) was recorded. The recognition index was 
defined as $\left(T_{2} B /\left(T_{2} A+T_{2} B\right) x 100\right)$. A recognition index of $50 \%$ corresponds to chance level whereas a higher recognition index reflects active recognition.

\section{Experimental design}

Optogenetic experiments. A first cohort of eNpHR transgenic mice $(n=29)$ received striatal 6OHDA $(n=18)$ or vehicle injections ( fibers as previously described. After a recovery period of two weeks, mice were tested in the EPM and the SI tests during optogenetic photoinhibition of ChIs. The two laser ON or OFF sessions were tested in the same animals in a counterbalanced manner interspaced by at least 8 days. Laser illumination was applied during the 5-min test period of the EPM and during the 4min presentation of the juvenile on $\mathrm{P} 2$ of the SI test. A second cohort of eNpHR transgenic lesioned $(n=23)$ or sham-treated $(n=14)$ mice, implanted with bilateral optic fibers in the striatum, were first tested for reversal learning in an operant nose-poke task (unpublished data) and then tested in the object recognition task 10 weeks post-lesion to assess the long-term effect of dopaminergic lesions. They were randomly assigned to one of two lesioned groups or two sham-treated groups according to laser condition ON or OFF: [sham-laser OFF $(n=7)$, sham-laser ON $(n=7), 6-O H D A-l a s e r$ OFF $(n=10)$ and 6-OHDA-laser ON $(n=13)]$ and were tested either in the spatial condition followed one week later by the non-spatial object recognition condition or in the inverse order. Laser photoillumination was applied during the recognition phase of the test (10 $\mathrm{min})$ to assess memory retention.

Pharmacological experiments. Two cohorts of mice were tested in the same behavioral tests to evaluate the effects of M1 muscarinic receptor blockade by i.p. injections of telenzepine 0.3 $\mathrm{mg} / \mathrm{kg}$. This dose of telenzepine was chosen because of its lack of effects in sham animals in a previous study. Telenzepine $0.3 \mathrm{mg} / \mathrm{kg}$ was also found to reverse the motor deficits produced by unilateral 6-OHDA lesions (Ztaou et al., 2016). Sham $(\mathrm{n}=19)$ and 6-OHDA $(\mathrm{n}=15)$ 
operated mice were tested between days 13 to 33 post-surgery once in the EPM and in the SI tests. Another group of sham $(n=18)$ and 6-OHDA $(n=22)$ mice was tested in the spatial and non-spatial recognition tasks in a random order. Telenzepine or vehicle was injected i.p. in all mice 30 min before either the elevated plus maze, the second presentation of social interaction test or the recognition phase of object recognition.

\section{Immunolabeling and histology}

Animals were deeply anesthetized with pentobarbital $(100 \mathrm{mg} / \mathrm{kg})$ and then transcardially perfused with an ice-cold solution of paraformaldehyde $4 \%$ in PBS. After dissection, brains were post-fixed overnight in the same fixative at $4{ }^{\circ} \mathrm{C}$, cryoprotected in $30 \%$ sucrose dissolved in $1 \mathrm{X}$ PBS for an additional $36 \mathrm{~h}$ at $4^{\circ} \mathrm{C}$ and frozen.

Coronal brain sections $(40 \mu \mathrm{m})$ covering the antero-posterior extent of the substantia nigra pars compacta $(\mathrm{SNc})$ and striatum were collected at $-20{ }^{\circ} \mathrm{C}$ with a Leica CM3050 S cryostat (Leica Microsystemes SAS, Nanterre, France) and kept free floating or mounted on superfrost plus slides depending on the experiment (immunostaining or Nissl staining on alternate sections). The dorsal hippocampus is long known to underlie visuospatial memory processes from the work of Olton and colleagues (Wible et al., 1992) and more recently by Bonito-Oliva et al., 2014), we thus evaluated if the partial lesion of the dopaminergic SNc neurons could impact dorsal hippocampus DA innervation. Coronal brain sections were thus also taken at the level of the dentate gyrus and processed for tyrosine hydroxylase (TH) immunostaining.

(1) TH immunostaining: TH immunostaining was performed in a selected group of sham and 6-OHDA lesioned animals at completion of the behavioral testing. Brain sections were permeabilized in phosphate buffer (PBS) with $0.4 \%$ Triton X-100 (PBST) for $30 \mathrm{~min}$ at room temperature. Sections were then incubated in a blocking solution composed of PBST 
with $3 \%$ bovine serum albumin and $10 \%$ normal goat serum for $1 \mathrm{~h}$ at room temperature. Sections were incubated overnight at $4^{\circ} \mathrm{C}$ in mouse anti-tyrosine hydroxylase $(\mathrm{TH})(1 / 1000$, Millipore, AB318). They were then incubated in Alexa Fluor 594 goat anti-mouse (1/500, Invitrogen, A11005). Immunostaining was done on free-floating sections, which were then mounted onto SuperFrost Plus glass slides (VWR) and coverslipped with FluorSave mounting media (Merck Chemicals). Four to six images of TH-immunostained alternated slices from each animal were acquired on a fluorescence microscope (Leitz Aristoplan light microscope) equipped with a Nikon high resolution digital camera (756 x 581 pixels; Nikon, Tokyo, Japan) with a 10x objective, interfaced to a PC computer and Image software (Lucia, Nikon). The number of TH-positive DAergic neurons in $\mathrm{SNc}$ was quantified in sections taken from -2.80 to -3.80 from bregma in a first group of selected subjects of behaving mice ( ham $n=3,6-O H D A n=11$, Fig. 1A,C). Slices were chosen to cover the entire rostral to caudal extension of the SNc. TH-positive cells in the SNc were counted manually in four regions of interest (ROIs, 1100x1100 $\mu \mathrm{m}$ ) per hemisphere, using the cell counter plugin of FIJI software (ImageJ, National Institutes of Health). ROIs were determined to cover the whole medio-lateral extension of the structure based on the stereotaxic mouse atlas (Paxinos \& Franklin, 2001). Cells number was calculated as the mean number/ROI. To detect potential loss of DA innervation of the dorsal hippocampus, TH staining intensity was also determined at the level of dentate gyrus (from anteriority level -1.34 to -2.18 from bregma) in two ROIs $(3000$ x $3000 \mu \mathrm{m})$ per hemisphere, using Image J software to evaluate the loss of catecholaminergic fibers. Quantification of TH immunostaining in the striatum, without tissue damage due to optic fibers implantation, was performed in an additional group of mice which received the same lesion procedure but were not evaluated behaviorally (sham $\mathrm{n}$ $=10,6-$ OHDA $n=12$, Fig. 1D). The extent of DA lesion in the striatum was expressed by the percentage of $\mathrm{TH}$ immunoreactivity of sham animals in the different structures. In this 
group, TH immunostaining was also measured in the SNc and dorsal hippocampus and the values compared to those obtained in the preceding group. $\mathrm{TH}$ immunoreactivity was calculated as the mean intensity value/ROI. In all cases, TH background was determined in the cortex of the same slice with three measures of the optical density that were then averaged for background subtraction. Each image and background-based thresholds were applied before analysis to account for small variances in the background between different slices and animals.

(2) Opsin and ChIs immunostaining: In transgenic Rosa ${ }^{\mathrm{eNpHR} /+}:: \mathrm{ChAT}^{\mathrm{cre} /+}$ mice, issued by crossing the LoxP-stop-eNpHR3.0-EYFP line (Ai39 mice) with the ChAT ${ }^{\text {cre/cre }}$ knockin line, we controlled that the opsin (eNpHR3.0) was indeed correctly expressed in cholinergic neurons. Co-expression of eNpHR tagged with the fluorophore EYFP and ChAT was determined at the level of the striatum and number of neurons counted in striatal coronal sections of two mice. Brain sections of the striatum were permeabilized in PBST for 30 min at room temperature. Sections were then incubated in a blocking solution composed of PBST with $3 \%$ bovine serum albumin and $10 \%$ normal goat serum for $1 \mathrm{~h}$ at room temperature. Brain sections were incubated overnight at $4^{\circ} \mathrm{C}$ in rabbit anti-GFP $(1 / 500$, Invitrogen, A11122) and goat anti-ChAT (1/100, Millipore, AB144P) for primary antibody exposure. They were then incubated, in Alexa Fluor 488 donkey anti-rabbit $(1 / 500$, Invitrogen, A21206) and Alexa Fluor 555 donkey anti-goat (1/500, Invitrogen, A21432) for $1 \mathrm{~h} 30$ at room temperature. Examination of eNpHR-EYFP in ChAT expressing neurons was performed in the striatum from bregma +1.54 to $-4.04 \mathrm{~mm}$ using confocal imaging with a Zeiss LM 710 NLO laser-scanning microscope equipped with a 63x/1.32 numerical aperture (NA) oil-immersion lens. 
(3) Control of optic fibers implantation. Alternate sections $(40 \mu \mathrm{m})$ were processed for Nissl staining with cresyl-violet to check the placement of optic fibers in each striatum and assess possible tissue damage. Reconstitution of the implantation sites was determined in serial coronal sections and reported in schematic photomicrographs taken from the atlas of Paxinos and Franklin (2001). Mice with incorrect placements or incomplete DA lesions were discarded from statistical analysis.

\section{Statistical analysis}

All behavioral analyses were conducted on littermates and the values are presented as mean \pm standard error of the mean (SEM). Immunofluorescence experiments. The effect of 6-OHDA lesion in each structure was analyzed using Student's t test. Optogenetic experiments. Effects of 6-OHDA lesion and optogenetic photoinhibition were tested by two-way repeated-measures ANOVA (for elevated plus maze and social interaction tests) or two-way ANOVA (for spatial and non-spatial recognitions tasks) with groups (6-OHDA versus sham) as between factor and laser (ON versus OFF) as within factor, followed by adapted post-hoc tests between groups (Bonferroni's multiple comparisons test). Pharmacological experiments. Effects of 6-OHDA lesion and telenzepine treatment were analyzed by two-way ANOVA, with groups (6-OHDA versus sham) as between factor and pharmacological treatment (telenzepine versus vehicle) as within factor, followed by adapted post-hoc tests between groups (Bonferroni's multiple comparisons test). Values of $\mathrm{p}<0.05$ were considered as significant for all analyses. Statistical analyses were performed using Prism6 (GraphPad software Inc., La Jolla, USA). 


\section{Results}

\section{Effects of bilateral striatal 6-OHDA lesions on TH immunoreactive neurons}

Bilateral 6-OHDA infusions in the dorsal striatum, quantified in a group of 11 lesioned and 3 sham mice, induced a partial loss of TH immuno-positive cells at different anteriority levels of the substantia nigra pars compacta $(\mathrm{SNc})$ sparing the ventral tegmental area (VTA), as illustrated in Figure 1A. We expanded our examination of striatal 6-OHDA-induced DA denervation at the level of the striatum in an additional group of mice that were not implanted with optic fibers in the striatum. 6-OHDA lesions induced a partial loss of $\mathrm{TH}$ immunofluorescence extending in the rostro-caudal extent but not in the ventral striatum (Figure 1B). In this group, TH-positive cells decreased to $47.5 \%$ (range 30-70 \%) in the SNc compared to sham mice (Student's $t$ test, $t_{16}=3.35, P=0.004$, Fig. 1C) and $\mathrm{TH}$ immunoreactivity in the striatum was decreased to a level of $40 \%$ of control animals (Student's $t$ test, $t_{20}=3.66, P=0.002$, Fig. 1D). Correlation between the level of expression of $\mathrm{TH}$ immunoreactivity in the striatum and the loss of TH-positive cells in the SNc could be measured in ten lesioned subjects with a similar number of slices taken in the two structures. Statistical analysis revealed a strong correlation (Pearson's $r=0.71, P=0.02$ ) (Figure 1E). A similar decrease of TH-positive cells averaging 53\% (range 35-70 \%) in the SNc was found in the first group of lesioned mice (Student's $t$ test, $t_{12}=4.32, P=0.001$, not illustrated). At the level of the dorsal hippocampus, TH immunostaining tended to be reduced in 6-OHDA groups, although it did not reached significant level whatever the group (Student's $t$ test, $t_{12}=0.86, P=$ 0.4 and $t_{10}=1.40, P=0.19$, respectively, not illustrated).

These partial striatal DA depletion did not induce any major motor disabilities, contrary to the total unilateral nigrostriatal DA lesion as previously described. Consistent with that, the spontaneous locomotor activity measured in each behavioral test was not different between sham and 6-OHDA groups (See Table 1). 


\section{Opsin eNpHR-expression in the striatum of transgenic mice}

Transgenic lines of Rosa $a^{\mathrm{eNpHR} /+}$ (Ai39 mice) conditionally express the Halorhodopsin/EYFP fusion protein from the endogenous Gt(ROSA)26Sor locus. Crossing Ai39 mice with $\mathrm{ChAT}^{\mathrm{cre} / \mathrm{cre}}$ knock-in mice induces eNpHR3.0/EYFP expression in cholinergic neurons throughout the brain (Vandecasteele et al., 2014). We measured the co-expression of eNpHREYFP and ChAT at the level of the striatum in a selected number of transgenic $\mathrm{Rosa}^{\mathrm{eNpHR} /+}: \mathrm{ChAT}^{\mathrm{cre} /+}$ mice (transgenic eNpHR mice, $\mathrm{n}=2$ ) to control for the correct expression of the opsin (eNpHR) in cholinergic interneurons. In these transgenic mice, over 94\% of striatal neurons expressing the eNpHR-EYFP opsin were identified as ChATexpressing neurons (93.8\% and $96.2 \%$ in $n=122$ and $n=156$ neurons in two mice, Fig. 2A). We have previously shown by recording identified ChIs, in vitro in striatal slices and in vivo anesthetized eNpHR transgenic mice, that the opsin was functional after laser illumination. In vivo, yellow laser $(589 \mathrm{~nm})$ continuous illumination of striatal ChIs for up to $3 \mathrm{~min}$ led to reversible photoinhibition of action potential firing activity in ChIs (Maurice et al., 2015; Ztaou et al., 2016). Figure 2B shows schematic reconstructions of optical fiber illumination sites in the dorsal striatum at different anteriority levels, from +0.74 to $+0.14 \mathrm{~mm}$ related to bregma. Nissl Cresyl violet staining shows the locations of the optic fibers on coronal sections at the level of striatum of representative subjects. There was no obvious tissue damage caused by relatively long period of light illumination as illustrated in a Nissl-stained section (Fig. 2B). Optical fibers were localized in the medial part of the dorsal striatum. Subjects with incorrect placement sites located outside the dorsal striatum were excluded from statistical analysis.

\section{Photoinhibition of striatal ChIs activity reverses non-motor parkinsonian-like symptoms}

We examined the impact of optogenetic photoinhibition of striatal ChIs on several behavioral tests indexing anxiety-like behavior and memory deficits induced by partial nigrostriatal DA 
lesions.

To evaluate anxiety-like behavior, sham and 6-OHDA transgenic eNpHR mice were tested in the elevated plus maze after laser illumination $(\mathrm{ON})$ and in OFF conditions. There was no difference of the order of photollumination (laser ON first and laser OFF or the opposite condition) on mice performance in the EPM or the SI. Two-way repeated-measures ANOVA revealed a significant lesion $\mathrm{x}$ laser interaction on the time spent, distance traveled and number of entries in open arms (Figure 3A) (time: $F_{1,19}=4.67, P=0.04$; distance: $F_{1,19}=5.79, P=$ 0.02; entries: $F_{1,19}=5.05, P=0.03$ ). In comparison with sham, 6-OHDA mice spent significantly less time in open arms than in the closed arms (Bonferroni's test, $P=0.003$ ). They also showed a decrease of distance traveled and number of entries (Bonferroni's test, $P<$ 0.0001 and $P=0.002$, respectively) in the open arms (Figure 3A). Bilateral yellow laser (589 $\mathrm{nm}$ ) illumination of striatal ChIs did not affect the phenotype in sham group (Bonferroni's test, laser ON versus OFF conditions, for time, distance and number of entries in the open arms, $P>$ 0.99, $P>0.99, P=0.96$, respectively) whereas it significantly increased the time spent, distance traveled and number entries in open arms in 6-OHDA mice (Bonferroni's test, laser ON versus $\mathrm{OFF}$, time: $P=0.001$; distance: $P=0.0003$; entries: $P=0.0004)$. This reflects an anxiolytic-like effect of the photoinhibition of striatal ChIs only in 6-OHDA mice. No significant difference of the total distance traveled in the entire maze (global locomotion) was found between groups $\left(F_{1,19}=2.47, P=0.13\right)$ (Table 1$)$, showing that the anxiolytic-like phenotype produced by a partial 6-OHDA lesion was not produced by a reduction of motor activity. The photoinhibition of striatal ChIs did not modify the global exploratory behavior either in control or 6-OHDA-lesioned mice.

To investigate short-term social memory in 6-OHDA-lesioned mice, we tested the ability of adult mice to recognize a juvenile congener after a second exposure interspaced by a 30-min interval, illustrated by videotracking paths of the mice toward the center of the openfield, where 
the juvenile is placed under a grid (Fig. 3B). Data were analyzed as a ratio of the contacts duration and number of contacts toward the juvenile congener between the second presentation (P2) and the first presentation (P1). A low ratio indicated that the juvenile was recognized at the second presentation. Two-way repeated-measures ANOVA revealed a significant lesion $\mathrm{x}$ laser interaction on the ratio comparing the contacts durations and number of contacts during P2 to P1 (contacts duration: $F_{1,18}=11.69, P=0.003$; number of contacts: $F_{1,18}=4.29, P=$ 0.05). In comparison with sham, 6-OHDA mice clearly did not identified the juvenile, as found by a significant increase of the ratio P2/P1 (Figure 3B) (Bonferroni's test, $P<0.0001$ and $P=$ 0.003, respectively). Photoinhibition of striatal ChIs in 6-OHDA mice significantly restored the recognition of the juvenile (Bonferroni's test, laser ON versus OFF, contacts duration: $P=$ 0.0006; number of contacts: $P=0.04$ ). No significant difference of locomotor activity in the open field was found between the two presentations and between groups $\left(F_{3,36}=0.48, P=0.39\right)$ (Supplemental table).

We then carried out further experiments to assess the role of striatal ChIs on visuospatial memory and novel object recognition processing. The videotracking of the paths and manual counting off-line of sham animals revealed an active object recognition in the spatial (Figure 3C) and non-spatial (Figure 3D) versions of the task. There was no difference in the time spent investigating the displaced or novel objects whether mice were tested first in the SRO or in NSRO conditions. Two-way ANOVA showed a significant lesion $\mathrm{x}$ laser interaction on recognition index in the spatial recognition task (Figure $3 C)\left(F_{1,32}=8.33, P=0.006\right)$. 6OHDA-lesioned mice spent a similar amount of time investigating the familiar or displaced object as shown by a significant decrease of the recognition index (Bonferroni's test, $P=$ 0.0007). Photoinhibition of striatal ChIs in 6-OHDA mice significantly restored the recognition index (Bonferroni's test, laser ON versus OFF, $P=0.002$ ) without affecting global locomotor activity $\left(F_{1,32}=2.61, P=0.11\right)$ (Table 1$)$. Interestingly, no effect of either 6-OHDA lesion or 
photoinhibition of striatal ChIs was observed in the non-spatial recognition task (Figure 3D) $\left(F_{1,32}=0.006, P=0.93\right)$ indicating that 6-OHDA lesion only impaired the spatial discrimination but not the novelty detection.

\section{M1 mACh receptor blockade restores control level of anxiety and social interaction}

Muscarinic cholinergic receptor subtypes M1 are highly expressed in the striatum (Bonsi et al., 2011) and the pharmacological blockade with a preferential M1 mACh receptor antagonist, telenzepine at a dose of $0.3 \mathrm{mg} / \mathrm{kg}$, was previously found to reverse motor impairment in the unilateral 6-OHDA model of PD (Ztaou et al., 2016). To study whether M1 mACh receptor blockade could also be beneficial in restoring emotional and cognitive functions, injections of telenzepine $0.3 \mathrm{mg} / \mathrm{kg}$ i.p. were tested in another group of sham and 6-OHDA lesioned mice. In the EPM, a two-way ANOVA revealed a significant lesion $\mathrm{x}$ treatment interaction on the time spent, distance traveled in open arms (time: $\mathrm{F}_{1,30}=4.35, P=0.04$; distance: $\mathrm{F}_{1,30}=4.75, P=$ 0.03 ) and a tendency on the number of entries in open arms $\left(\mathrm{F}_{1,30}=2.76, P=0.10\right)$. In comparison with sham group, 6-OHDA mice spent significantly less time in open arms (Bonferroni's test, $P=0.0017$ ) and showed a decrease of distance traveled (Bonferroni's test, $P$ $=0.0017$ ) (Figure 4A). Intraperitoneal injection of telenzepine at a dose of $0.3 \mathrm{mg} / \mathrm{kg}$, did not affect the phenotype in sham group (Bonferroni's test, 0.3 versus $0 \mathrm{mg} / \mathrm{kg}$, time: $P>0.9999$; distance: $P>0.75$ ) whereas it increased the time and the distance traveled in open arms in 6OHDA mice (Bonferroni's test, 0.3 versus $0 \mathrm{mg} / \mathrm{kg}$, time: $P=0.03$; distance: $P=0.04$ ). No significant difference of the global locomotion traveled in the maze was found between group, regardless of telenzepine treatment $\left(F_{1,30}=0.20, P=0.66\right)$.

In the SI test, two-way ANOVA revealed a significant lesion $\mathrm{x}$ treatment interaction on the ratio comparing the contacts durations and number of contacts during P2 to P1 (contacts duration: $F_{1,30}=10.47, P=0.003$; number of contacts: $\left.F_{1,30}=7.62, P=0.009\right)$. In comparison 
with sham, 6-OHDA mice did not identify the juvenile, as found by a significant increase of the ratio $\mathrm{P} 2 / \mathrm{P} 1$ (Bonferroni's test, $P=0.0004$ and $P=0.003$, respectively) (Figure 4B). Intraperitoneal injection of telenzepine in 6-OHDA mice significantly restored the recognition of the juvenile (Bonferroni's test, 0.3 versus $0 \mathrm{mg} / \mathrm{kg}$, contacts duration: $P=0.0008$; number of contacts: $P=0.006)$. No significant difference of locomotor activity in the open field was found between the two presentations and between groups $\left(F_{3,30}=0.29, P=0.84\right)$ (Supplemental table).

Visuospatial memory deficits and novelty detection were then assessed after telenzepine i.p. injection. Two-way ANOVA revealed no significant lesion $\mathrm{x}$ treatment interaction on recognition index in the SRO task (Figure $5 \mathrm{C})\left(F_{1,38}=0.83, P=0.37\right)$ but a significant main effect of lesion $\left(F_{1,38}=122.20, P<0.0001\right)$ and no effect of telenzepine treatment $\left(F_{1,38}=2.25\right.$, $P=0.14)$. Global locomotor activity was not affected by 6-OHDA or telenzepine treatment in the SRO task $\left(F_{1,38}=0.58, P=0.45\right)$. No effect of either 6-OHDA lesion or telenzepine treatment was observed in the NSRO task (Figure 5D) $\left(F_{1,36}=1.38, P=0.25\right)$ and in locomotor activity $\left(F_{1,36}=0.04, P=0.85\right)$.

\section{Discussion}

Cholinergic interneurons (ChIs) play a crucial role in the regulation of striatal functions and in the pathophysiology of basal ganglia disorders. In the present study, we used optogenetic photoinhibition of striatal ChIs in mice with mild dopamine (DA) depletion of the striatum mimicking a prodromal stage of PD to assess their role in non-motor dysfunctions of Parkinson's disease (PD). Our results show that striatal ChIs photoinhibition reduces anxiety, short-term social and spatial memory impairment of 6-OHDA-lesioned mice. Telenzepine, a muscarinic M1 receptor antagonist, injected peripherally diminishes the anxiety level and restores the recognition of the juvenile in the social interaction test, without affecting 
visuospatial memory impairment.

\section{Partial 6-OHDA nigrostriatal lesions disrupt emotional and cognitive processes}

Early cognitive deficits and mood disorders precede the hallmark motor symptoms of PD patients, do not respond well to dopamine therapy and impact deeply the quality of life. Therefore, animal models of prodromal stage of the disease may help to find new pharmacologic targets for palliative and neuroprotective treatments. As previously found in mice (Bonito-Oliva et al., 2014; De Leonibus et al., 2007), the neurotoxin 6-OHDA injected at low concentration in the dorsal striatum induces a retrograde neurodegeneration of DA neurons in the SNc averaging 53\% loss of TH-positive cells. These levels of DA cell loss can be reproduced in different groups of mice as found here associated with a partial decrease (40\%) of $\mathrm{TH}$ immunoreactivity in the striatum. In a previous study, using biochemical analysis ex vivo of tissue levels of DA and its metabolites in sham and 6-OHDA lesioned mice, we found a positive correlation between the visuospatial deficits in the spatial object recognition task and the tissue levels of dopamine within the dorsal striatum. The less dopamine in the dorsal striatum the worst was the deficit in detecting spatial changes (De Leonibus et al. 2007). Furthermore, we demonstrated that variable behavioral traits affecting akinetic or attentional and cognitive processes could be related to the extent of DA depletion in rats with partial striatal 6-OHDA lesions (Amalric et al., 1995; Mourre et al., 2017). Variability in the extent of DA lesions within animals of each group are also found in other models of early PD, such as the $\alpha$-synuclein models in mice transgenic for truncated human $\alpha$-synuclein, which show no loss of nigral DA neurons but a progressive decreased level of striatal DA accounting for plasticity changes in cholinergic interneurons (Tozzi et al., 2016; Magen \& Chesselet, 2010). Here we found that partial 6-OHDA lesions may have long-lasting cognitive deficits as evidenced by the impairment of object recognition in a subgroup of mice tested 10 weeks post- 
lesion in the spatial version of the object recognition.

Despite the variability of the striatal 6-OHDA lesions, they induced profound short-term memory impairment in social investigation of the juvenile and spatial object recognition. Interestingly, the novel object was recognised by the lesioned mice suggesting that their ability to discriminate a novel object from a familiar one was not impaired nor due to a diminished exploratory behavior. Cognitive symptoms in PD patients include deficits in visuospatial discrimination, working memory, attention processes and flexibility which can be related to both striatal and prefrontal dysfunction (Chaudhuri et al., 2006; 2011; Owen et al., 1993). In addition, the increased level of anxiety-like behaviour observed in our 6-OHDA lesioned mice in the elevated plus maze may be related to the anxiety disorders that are seen in a considerable percentage of parkinsonian patients well before the motor symptoms are evident (Chaudhuri et al., 2006; 2011; Meissner, 2012). There was no change in total time spent in the elevated plusmaze compared to controls, nor in the total distance traveled in the open field demonstrating that the behavioral deficits were not secondary to motor impairment.

\section{Contribution of striatal cholinergic interneurons to cognitive impairment and anxiety in a prodromal model of $\mathrm{PD}$}

The imbalance between ACh and DA activity in the striatum is central to the development of motor symptoms of PD (Pisani et al., 2007). Whether the activity of the striatal cholinergic system is also affected by a mild nigrostriatal DA denervation, when motor symptoms are not manifest, is largely unknown. We thus first verified that ChIs photoinhibition did not alter the exploratory behavior of mice while performing tests. Silencing ChIs did not affect the locomotion activity in the three different tests. ChIs selective elimination by immunotoxinmediated cell targeting in the the dorsomedial striatum had no effect on locomotion either 
(Okada et al., 2014). ChIs photoinhibition did not produce any memory impairment nor changes in anxiety level in controls (sham-operated mice), suggesting that the laser light by itself did not produce any uncontrolled effect. In our transgenic mice the co-expression of eNpHR-EYFP and ChAT was present in most of cholinergic interneurons (over $94 \%$ overlay) at the level of the striatum ruling out the possibility that the laser light would not affect the opsins. The continuous photoillumination conditions for 5 to $10 \mathrm{~min}$, depending on the test, has been previously found to cause no physical damage to the brain tissue (Gradinaru et al., 2009; Yizhar et al., 2011). As previously demonstrated, the laser power levels were sufficient to inhibit neuronal activity without causing adverse effects. In fact, a continuous light stimulation of 5-min duration significantly alleviated motor deficits in the extensive model of PD while a 3-min photoillumination of striatal cholinergic neuronal activity in anesthetized mice was found to inhibit action potentials in the striatum in a reversible manner (Ztaou et al., 2016). Furthermore, ChIs photoinhibition did not modify the membrane excitability of striatal medium spiny neurons (MSNs) in sham animals (Maurice et al., 2015). Optogenetic inhibition of ChIs in sham-operated mice did not affect recall memory nor learning, did we therefore apply ChIs photoinhibition in the recall phase of spatial memory that was disrupted by partial 6-OHDA lesions. In 6-OHDA-lesioned mice, photoinhibition of striatal ChIs fully reversed visuospatial discrimination, social recognition impairment and anxiety-like behavior. The beneficial effects of silencing ChIs on short-term memory processes and anxiety phenotype may be directly linked to the reduction of the pathological increased striatal cholinergic tone in the core of the lesion and the resulting changes in ChIs excitability, although this remains to be demonstrated. We indeed aimed at illuminating the dorsal and medial part of the striatum (DMS) as illustrated in Figure 2B, close to the core of the bilateral 6-OHDA infusions in the dorsal part of the striatum. The restricted 6-OHDA infusion in the striatum is likely to produce a gradient in the lesioned area. The loss of DA fibers within the core of the lesion could result in an increased 
cholinergic tone disrupting short-term memory processes, however, the restricted striatal DA denervation would not alter motor activity. In addition, the role that striatal cholinergic activity plays in new learning and synaptic plasticity depends on the posterior DMS (Bradfield et al., 2013). Changes of synaptic plasticity appear to depend on cholinergic tone (Hasselmo \& Bower 1993; Ragozzino et al., 2009), therefore transiently suppressing cholinergic activity locally in the striatum may restore the control level of ACh enabling recognition of familiar animal or object in the social interaction and spatial version of the object recognition. Other mechanisms might be involved in a model of early $\mathrm{PD}$, such as the impairment of long-term potentiation (LTP) in striatal ChIs (but not in MSNs) produced by overexpression of wild-type human $\alpha$ synuclein in the rat SNc (Tozzi et al., 2016). The partial reduction of striatal DA level is associated with reduced cognitive performance in an active avoidance test, supporting the view that the loss of synaptic plasticity in ChIs may represent a precocious marker of cognitive dysfunction in PD (Tozzi et al., 2016).

Silencing ChIs could act through different mechanisms to restore or partially mimic the pause of ChI firing well known in the literature to be crucial for learning processes, which happened to be disrupted by the 6-OHDA lesion (Aosaki et al., 1994; 2010). In addition to the striatal dopaminergic dysfunction, other pathological features may generate hippocampal-dependent memory deficits in PD (Churchyard \& Lees, 1997). Reduction in TH immunoreactivity in the hippocampus, produced by striatal 6-OHDA lesions, disrupt LTP in the dentate gyrus and impair long-term object memory recognition (Bonito-Oliva et al., 2014). There was a nonsignificant reduction in TH immunoreactivity in the dorsal hippocampus in the present model of early PD that could not account alone for the visuospatial and discriminatory memory deficits. Furthermore, striatal ChIs photoinhibition fully restored short-term memory 
recognition, pointing to a critical role of cholinergic interneurons of the striatum in these processes.

\section{Modulation of M1 muscarinic cholinergic receptors reverses non-motor deficits}

Muscarinic cholinergic receptor subtypes M1 and M4 have a predominant expression in the striatum as compared with M2 and M3 subtypes (Bonsi et al., 2011). Here, we found that the systemic injection of the M1 mAChR preferential antagonist telenzepine is anxiolytic and restores an efficient recognition in the social interaction that was disrupted in partially DAdepleted mice. In humans, studies reported cognitive deficits in parkinsonian patients in advanced stages - likely described as frontal lobe deficits due to a direct consequence of impaired mesocortical dopaminergic transmission - when treated by non-selective mAChR antagonists such as scopolamine (Langmead et al., 2008; Müller \& Bohnen, 2013). The lack of selectivity of pharmacological compounds make the interpretation of mechanism of action unclear. Newman \& Gold (2016) showed that the cholinergic tone that is too low or too high is related to poor cognitive functions, depending on the task. In their study, scopolamine, alters memory processes by acting on postsynaptic mAChRs. But it also acts on presynaptic M2 mAChRs, thus increasing the release of $\mathrm{ACh}$, and accordingly improves memory processes (Newman \& Gold, 2016). In the present study the lack of effect of telenzepine in reversing spatial memory impairment (in comparison with social memory recognition) could result from these puzzling effects.

Telenzepine, at a dose of $0.3 \mathrm{mg} / \mathrm{kg}$, does not disrupt anxiety level, object or social recognition of sham animals, unlike other non-selective cholinergic antagonists such as scopolamine which are known to alter memory processes at high concentration. In fact, the beneficial effects of telenzepine at this low concentration are only observed here after the degeneration of the 
nigrostriatal DA pathway producing an imbalance between ACh and DA activity in the striatum. The disruption of the DA/ACh balance was found to be crucial in the ventral striatum where an enhanced activation of ACh in the nucleus accumbens shell generate a variety of aversive behaviors, including depression, anhedonia, and anxiety (Chen et al., 2012). The results obtained with telenzepine suggest that increased cholinergic activity in the striatum may underlie the anxiety-like behavior produced by partial 6-OHDA lesions. We cannot neglect that systemic injection of telenzepine targets also M1 mAChRs located in others brain areas. Indeed, the hippocampus - structure well-known to be implicated in memory processes expressed mainly M1 receptors (36\% in comparison to others mAChRs) (Volpicelli \& Levey, 2004). The lack of effect of systemic telenzepine on spatial recognition might thus be due to an opposite action of telenzepine in the striatum and the hippocampus.

In conclusion, while inhibiting cholinergic signaling may rescue the motor dysfunctions seen with PD in the late stage of the disease, our study shows that the critical DA/ACh imbalance may also underlie the short-term memory dysfunction observed in the early phase of the disease. Systemic blockade of M1 mAChRs improves anxiety behavior-like and short-term memory in the prodromal mice model of PD, however its effect on memory processes (1) is dependent upon an optimal level of ACh release and, (2) seems not to be due to a specific action in the striatum. Moreover, our study focus on M1 mAChRs, one of the subtypes highly expressed in the striatum (Conti et al., 2017). We however cannot neglect that ChIs activity is also driven on nicotinic receptors which contributes to elevate the striatal DA release (Threlfell \& Cragg, 2011; Threlfell et al., 2012). 


\section{Legends}

Figure 1. Extension of dopaminergic lesions after bilateral 6-hydroxydopamine (6-OHDA) injections in the striatum.

A. Immunofluorescence images showing TH-positive cells in the substantia nigra (SN) and the ventral tegmental area (VTA) of representative mice of sham (left) and 6-OHDA (right) groups. Scale bar: $1 \mathrm{~mm}$.

B. Loss of $\mathrm{TH}$ immunoreactivity in the dorsal striatum at two anteriority levels in controls (Sham, left) or after bilateral 6-OHDA lesions (6-OHDA, right). Dotted lines delineates the extension of the TH immunoreactivity in the striatum. Cx, Cortex; Cc, corpus callosum; dStr: dorsal Striatum; NAcc: Nucleus accumbens. Scale bar: $1 \mathrm{~mm}$.

C-D. Quantification of TH immunoreactivity the striatum (C) and TH-positive cells in the SNc (D) in sham $(n=10)$ and 6-OHDA $(n=12)$ mice. Data are expressed as percentage of sham and shown as mean \pm SEM. Student's $t$ test: $* P<0.01$ versus sham group.

E. Correlation between $\mathrm{TH}$ immunoreactivity in the striatum and $\mathrm{TH}$-positive cells in the substantia nigra pars compacta ( $\mathrm{SNc}$ ). Statistical analysis reveals a correlation between the loss of TH+ cells and the decrease of TH immunoreactivity in the striatum (Pearson's $\mathrm{r}=0.7101, P$ $=0.0214)$.

Figure 2. Expression of halorhodopsin (eNpHR) in cholinergic interneurons (ChIs) of the dorsal striatum and location of optic fibers in the striatum.

A. Co-expression of eNpHR in ChAT-expressing neurons, identified as ChIs, in the striatum of eNpHR transgenic mice at different enlargements. Left, scale bar: $200 \mu \mathrm{m}$, right, enlargement of indicated squares, scale bar: $50 \mu \mathrm{m}$. Cx: cortex, Str: striatum, LV: lateral ventricle. 
B. Schematic reconstruction of the optical illumination sites in sham $(n=6)$ and 6-OHDA $(n=$ 12) mice in the dorsal striatum at different anteriority levels, from +0.74 to $+0.14 \mathrm{~mm}$ related to bregma. Below: Example of Nissl cresyl violet staining showing the trace of optic fibers implantation in the medial striatum. Scale bar: $1 \mathrm{~mm}$.

Figure 3. Effect of photoinhibition of striatal ChIs activity on emotional and memory dysfunction in 6-OHDA-lesioned mice.

Effects of photoinhibition of striatal ChIs in the elevated plus maze (A), social interaction (B), spatial object recognition (C) and non-spatial object recognition (D) tasks. Each dot represents the individual value of one single mouse.

A. Percentage of time spent, distance traveled and number of entries in open arms in the elevated plus maze. Sham $(n=8)$ and 6-OHDA $(n=13)$ groups performed the test under two conditions: laser OFF and laser ON. Values are shown as mean \pm SEM. Bonferroni's test after significant two-way repeated-measures ANOVA: ${ }^{*} P<0.01$ versus sham-laser OFF; $\# P<0.01$ in comparison between laser $\mathrm{ON}$ and $\mathrm{OFF}$.

B. Left: Representative paths of sham mice showing an active recognition of the juvenile mouse. Right: Ratio comparing the duration of contacts (in sec) and number of contacts during the second presentation $(\mathrm{P} 2)$ to the first presentation $(\mathrm{P} 1)$ of a same juvenile, for sham $(\mathrm{n}=8)$ and 6-OHDA $(\mathrm{n}=12)$ group, under two conditions: laser OFF and laser ON. Values are shown as mean \pm SEM. Bonferroni's test after significant two-way repeated-measures ANOVA: $* P$ $<0.01$ versus sham-laser OFF; \#P<0.05 in comparison between laser $\mathrm{ON}$ and OFF.

C-D. Left: Representative paths of sham mice showing an active recognition during the spatial object recognition (C) and non-spatial object recognition (D) tasks. Right: Recognition index for the spatial (C) and non-spatial (D) object recognition version of the task measured in the four groups: sham-laser OFF $(n=7)$, sham-laser ON $(n=6), 6-O H D A-l a s e r$ OFF $(n=10)$ and 
6-OHDA-laser ON $(n=13)$. Data are reported as mean \pm SEM. Bonferroni's test after significant two-way ANOVA: $* P<0.01$ versus sham-laser OFF; $\# P<0.01$ in comparison between laser ON and OFF.

Figure 4. Effects of M1 mAChR antagonist systemic injection on anxiety-like behavior and cognitive deficits in 6-OHDA-lesioned mice.

Effects of the M1 mAChR antagonist telenzepine, injected i.p. at a dose of $0.3 \mathrm{mg} / \mathrm{kg}$, in the elevated plus maze (A), social interaction (B), spatial object recognition (C) and non-spatial object recognition (D) tasks. Each dot represents the individual value of one single mouse.

A. Percentage of time spent, distance traveled and number of entries in open arms in the elevated plus maze measured in one cohort divided in four groups: sham-vehicle $(n=9)$, shamtelenzepine $(\mathrm{n}=10), 6$-OHDA-vehicle $(\mathrm{n}=8)$ and 6-OHDA-telenzepine $(\mathrm{n}=7)$. Values are shown as mean \pm SEM. Bonferroni's test after significant two-way repeated-measures ANOVA: $* P<0.01$ versus sham-vehicle group; $\# P<0.05$ in comparison between telenzepine and vehicle.

B. Ratio comparing the duration of contacts (in sec) (left) and number of contacts (right) during the second presentation (P2) to the first presentation (P1) of a same juvenile, in the same cohort than the elevated plus maze experiment. Values are shown as mean \pm SEM. Bonferroni's test after significant two-way repeated-measures ANOVA: $* P<0.01$ versus sham-vehicle; \#P $<0.01$ in comparison between telenzepine and vehicle.

C-D. Recognition index for the spatial displacement of the object (C) and non-spatial novel object recognition (D) in a second cohort divided in four groups: sham-vehicle $(\mathrm{n}=9-10)$, sham-telenzepine $(n=9), 6-O H D A-v e h i c l e(n=10-11)$ and 6-OHDA-telenzepine $(n=12)$. Data are reported as mean \pm SEM. Bonferroni's test after significant two-way ANOVA: *P $<0.01$ versus sham-vehicle group. 
Table 1. Locomotor activity measured in emotional and cognitive tests after striatal cholinergic interneurons photoinhibition or M1 muscarinic cholinergic receptor blockade with telenzepine (3 mg/kg i.p.).

Global locomotor activity represents the total distance covered in each apparatus measured in $\mathrm{cm}$ (mean $\pm \mathrm{SEM}$ ) during the testing period of the elevated plus maze, social interaction, spatial and non-spatial object recognition experiments. Two-way ANOVA with groups (6-OHDA versus sham) as between factor and pharmacological treatment (treatment versus vehicle) as within factor showed no significant difference of global locomotor activity in the maze or open field.

ANOVA, analysis of variance; 6-OHDA, 6-hydroxydopamine; P1, first presentation; P2, second presentation. ${ }^{\mathrm{a}} F_{1,19}=2.47, P=0.13 ;{ }^{\mathrm{b}} F_{3,36}=0.48, P=0.39 ;{ }^{\mathrm{c}} F_{1,32}=2.61, P=0.11$; ${ }^{\mathrm{d}} F_{1,32}=0.62, P=0.43 ;{ }^{\mathrm{e}} F_{1,30}=0.20, P=0.66 ;{ }^{\mathrm{f}} F_{3,30}=0.29, P=0.84 ;{ }^{\mathrm{g}} F_{1,38}=0.58, P=0.45 ;$ ${ }^{\mathrm{h}} F_{1,36}=0.04, P=0.85$. 


\section{Acknowledgments}

The authors declare no competing financial interests. This research was supported by the CNRS, Aix-Marseille University, French Ministry of Education and Research, France Parkinson Association, Borsa di Perfezionamento all'estero CUN 6/2016, National Research Agency (ANR-2010-1416) and within the context of the DHUNE project supported by A*MIDEX project (ANR-11-IDEX-0001-02). We would like to thank V. Gilbert and E. Mansour for animal care, D. Paleressompoulle and D. Louber for technical assistance, A. Tonetto for expertise in confocal microscopy.

Data are available via request to the authors. None of the authors has a conflict of interest.

\section{Author contributions}

S.Z. Designed study, performed experiment, analysed data, wrote paper

J.L. Performed experiment

I.W. Performed experiment

G.T. Performed experiment, analysed data, wrote paper

M.A. Designed study, analysed data, wrote paper 


\section{Abbreviations}

6-OHDA 6-hydroxydopamine

ACh Acetylcholine

ANOVA Analysis of variance

ChAT Choline acetyltransferase

ChIs Cholinergic interneurons

DA Dopamine

DMS Dorsomedial striatum

eNpHR Halorhodopsin

EYFP Enhanced yellow fluorescent protein

i.p. Intraperitoneal

i.s. Intrastriatal

LTP Long-term potentiation

mAChRs Muscarinic cholinergic receptors

MSNs Medium spiny neurons

P1 First presentation

P2 Second presentation

PD Parkinson's disease

PNN Pedunculopontine nucleus

SNc Substantia nigra pars compacta

TH Tyrosine hydroxylase

VTA Ventral tegmental area 


\section{References}

Aliane, V., Pérez, S., Bohren, Y., Deniau, J.-M., \& Kemel, M.-L. (2011) Key role of striatal cholinergic interneurons in processes leading to arrest of motor stereotypies. Brain,134, $110-118$.

Amalric, M., Moukhles, H., Nieoullon, A., \& Daszuta, A. (1995) Complex deficits on reaction time performance following bilateral intrastriatal 6-OHDA infusion in the rat. Eur J Neurosci, 7, 972-980.

Apicella, P. (2017) The role of the intrinsic cholinergic system of the striatum: What have we learned from TAN recordings in behaving animals? Neuroscience, 360, 81-94.

Aosaki, T., Graybiel, AM., Kimura, M. (1994) Effect of the nigrostriatal dopamine system on acquired neural responses in the striatum of behaving monkeys. Science, 265, 412-415.

Aosaki, T., Miura, M., Suzuki, T., Nishimura, K., \& Masuda, M. (2010) Acetylcholinedopamine balance hypothesis in the striatum: An update. Geriatrics \& Gerontology International, 10, S148-S157.

Beer, Z., Chwieśko, C., \& Sauvage, M.M. (2014) Processing of spatial and non-spatial information reveals functional homogeneity along the dorso-ventral axis of CA3, but not CA1. Neurobiol Learn Mem, 111, 56-64.

Blandini, F. \& Armentero, M.-T. (2012) Animal models of Parkinson's disease. FEBS Journal, 279, 1156-1166.

Bohnen, N.I. \& Albin, R.L. (2011) The cholinergic system and Parkinson disease. Behav. Brain Res, 221, 564-573.

Bonito-Oliva, A., Masini, D., \& Fisone, G. (2014) A mouse model of non-motor symptoms in Parkinson's disease: focus on pharmacological interventions targeting affective 
dysfunctions. Front Behav Neurosci, 8, 290.

Bonsi, P., Cuomo, D., Martella, G., Madeo, G., Schirinzi, T., Puglisi, F., Ponterio, G., \& Pisani, A. (2011) Centrality of striatal cholinergic transmission in Basal Ganglia function. Front Neuroanat, 5, 6.

Braak, H., Del Tredici, K., Rüb, U., de Vos, R.A.I., Jansen Steur, E.N.H., \& Braak, E. (2003) Staging of brain pathology related to sporadic Parkinson's disease. Neurobiol. Aging, 24, $197-211$.

Bradfield, L.A., Bertran-Gonzalez, J., Chieng, B., \& Balleine, B.W. (2013) The thalamostriatal pathway and cholinergic control of goal-directed action: interlacing new with existing learning in the striatum. Neuron, 79, 153-166.

Brichta, L., Greengard, P., \& Flajolet, M. (2013) Advances in the pharmacological treatment of Parkinson's disease: targeting neurotransmitter systems. Trends Neurosci, 36, 543-554.

Calabresi, P., Picconi, B., Parnetti, L., \& Di Filippo, M. (2006) A convergent model for cognitive dysfunctions in Parkinson's disease: the critical dopamine-acetylcholine synaptic balance. Lancet Neurol, 5, 974-983.

Calabresi, P., Picconi, B., Tozzi, A., \& Ghiglieri, V. (2016) Interaction between basal ganglia and limbic circuits in learning and memory processes. Parkinsonism Relat. Disord, 22 Suppl 1, S65-S68.

Calabresi, P., Picconi, B., Tozzi, A., Ghiglieri, V., \& Di Filippo, M. (2014) Direct and indirect pathways of basal ganglia: a critical reappraisal. Nature Publishing Group, 17, 1022-1030.

Chaudhuri, K.R. \& Odin, P. (2010) The challenge of non-motor symptoms in Parkinson's disease. Prog. Brain Res, 184, 325-341.

Chaudhuri, K.R., Healy, D.G., \& Schapira, A.H.V. (2006) Non-motor symptoms of Parkinson's disease: diagnosis and management. Lancet Neurol, 5, 235-245. 
Chaudhuri, K.R., Odin, P., Antonini, A., \& Martinez-Martin, P. (2011) Parkinson's disease: the non-motor issues. Parkinsonism Relat. Disord, 17, 717-723.

Chen, Y.-W., Rada, P.V., Bützler, B.P., Leibowitz, S.F., \& Hoebel, B.G. (2012) Corticotropin-releasing factor in the nucleus accumbens shell induces swim depression, anxiety, and anhedonia along with changes in local dopamine/acetylcholine balance. Neuroscience, 206, 155-166.

Churchyard, A. \& Lees, A.J. (1997) The relationship between dementia and direct involvement of the hippocampus and amygdala in Parkinson's disease. Neurology, 49, $1570-1576$.

Conti, M.M., Chambers, N., \& Bishop, C. (2018) A new outlook on cholinergic interneurons in Parkinson's disease and L-DOPA-induced dyskinesia. Neurosci Biobehav Rev, 92, 6782.

Dautan, D., Huerta-Ocampo, I., Witten, I.B., Deisseroth, K., Bolam, J.P., Gerdjikov, T., \& Mena-Segovia, J. (2014) A major external source of cholinergic innervation of the striatum and nucleus accumbens originates in the brainstem. J Neurosci, 34, 4509-4518.

De Leonibus, E., Pascucci, T., Lopez, S., Oliverio, A., Amalric, M., \& Mele, A. (2007) Spatial deficits in a mouse model of Parkinson disease. Psychopharmacology,194, 517525.

Di Chiara, G., Morelli, M., \& Consolo, S. (1994) Modulatory functions of neurotransmitters in the striatum: ACh/dopamine/NMDA interactions. Trends Neurosci, 17, 228-233.

Eskow Jaunarajs, K.L., Bonsi, P., Chesselet, M.-F., Standaert, D.G., \& Pisani, A. (2015) Striatal cholinergic dysfunction as a unifying theme in the pathophysiology of dystonia. Prog. Neurobiol, 127-128, 91-107.

Francardo, V., Recchia, A., Popovic, N., Andersson, D., Nissbrandt, H., \& Cenci, M.A. (2011) Impact of the lesion procedure on the profiles of motor impairment and molecular 
responsiveness to L-DOPA in the 6-hydroxydopamine mouse model of Parkinson's disease. Neurobiol. Dis, 42, 327-340.

Goldberg, J.A. \& Reynolds, J.N.J. (2011) Spontaneous firing and evoked pauses in the tonically active cholinergic interneurons of the striatum. Neuroscience, 198, 27-43.

Gradinaru, V., Mogri, M., Thompson, K.R., Henderson, J.M., \& Deisseroth, K. (2009) Optical deconstruction of parkinsonian neural circuitry. Science, 324, 354-359.

Hasselmo, M.E. \& Bower, J.M. (1993) Acetylcholine and memory. Trends Neurosci, 16, $218-222$.

Hirsch, E.C., Graybiel, A.M., Duyckaerts, C., \& Javoy-Agid, F. (1987) Neuronal loss in the pedunculopontine tegmental nucleus in Parkinson disease and in progressive supranuclear palsy. Proc. Natl. Acad. Sci. U.S.A, 84, 5976-5980.

Jellinger, K. (1988) The pedunculopontine nucleus in Parkinson's disease, progressive supranuclear palsy and Alzheimer's disease. J. Neurol. Neurosurg. Psychiatr, 51, 540543.

Kalkonde, Y.V., Shelton, R., Villarreal, M., Sigala, J., Mishra, P.K., Barea-Rodriguez, E., Moretti, P., \& Ahuja, S.S. (2011) The CC chemokine receptor 5 regulates olfactory and social recognition in mice. Neuroscience, 197, 153-161.

Karachi, C., Grabli, D., Bernard, F.A., Tandé, D., Wattiez, N., Belaid, H., Bardinet, E., Prigent, A., Nothacker, H.-P., Hunot, S., Hartmann, A., Lehéricy, S., Hirsch, E.C., \& François, C. (2010) Cholinergic mesencephalic neurons are involved in gait and postural disorders in Parkinson disease. J Clin Invest, 120, 2745-2754.

Kish, S.J., Tong, J., Hornykiewicz, O., Rajput, A., Chang, L.-J., Guttman, M., \& Furukawa, Y. (2008) Preferential loss of serotonin markers in caudate versus putamen in Parkinson's disease. Brain, 131, 120-131.

Kreitzer, A.C. (2009) Physiology and pharmacology of striatal neurons. Neuroscience, 32, 
$127-147$.

Langmead, C.J., Austin, N.E., Branch, C.L., Brown, J.T., Buchanan, K.A., Davies, C.H., Forbes, I.T., Fry, V.A.H., Hagan, J.J., Herdon, H.J., Jones, G.A., Jeggo, R., Kew, J.N.C., Mazzali, A., Melarange, R., Patel, N., Pardoe, J., Randall, A.D., Roberts, C., Roopun, A., Starr, K.R., Teriakidis, A., Wood, M.D., Whittington, M., Wu, Z., \& Watson, J.M. (2008) Characterization of a CNS penetrant, selective M1 muscarinic receptor agonist, 77-LH-28-1. Br J Pharmacol, 154, 1104-1115.

Lelos, M.J. \& Dunnett, S.B. (2011) Aberrant dopamine transmission and cognitive dysfunction in animal models of Parkinson's disease. J Parkinsons Dis, 1, 151-165.

Lenz, J.D. \& Lobo, M.K. (2013) Optogenetic insights into striatal function and behavior. Behav. Brain Res, 255, 44-54.

Lester, D.B., Rogers, T.D., \& Blaha, C.D. (2010) Acetylcholine-dopamine interactions in the pathophysiology and treatment of CNS disorders. CNS Neurosci Ther, 16, 137-162.

Lim, S.A.O., Kang, U.J., \& McGehee, D.S. (2014) Striatal cholinergic interneuron regulation and circuit effects. Front Synaptic Neurosci, 6, 22.

Lister, R.G. (1987) The use of a plus-maze to measure anxiety in the mouse.

Magen, I. \& Chesselet, M.-F. (2010) Genetic mouse models of Parkinson's disease The state of the art. Prog. Brain Res, 184, 53-87.Psychopharmacology (Berl), 92, 180-185.

Maurice, N., Liberge, M., Jaouen, F., Ztaou, S., Hanini, M., Camon, J., Deisseroth, K., Amalric, M., Goff, L.K.-L., \& Beurrier, C. (2015) Striatal Cholinergic Interneurons Control Motor Behavior and Basal Ganglia Function in Experimental Parkinsonism. Cell Reports, 1-11.

Meissner, W.G. (2012) When does Parkinson's disease begin? From prodromal disease to motor signs. Rev. Neurol. (Paris), 168, 809-814.

Michelle Lewis, L., Sheffler, D., Williams, R., Bridges, T.M., Kennedy, J.P., Brogan, J.T., 
Mulder, M.J., Williams, L., Nalywajko, N.T., Niswender, C.M., Weaver, C.D., Conn, P.J., \& Lindsley, C.W. (2008) Synthesis and SAR of selective muscarinic acetylcholine receptor subtype 1 (M1 mAChR) antagonists. Bioorganic \& Medicinal Chemistry Letters, 18, 885-890.

Mourre, C., Manrique, C., Camon, J., Aidi-Knani, S., Deltheil, T., Turle-Lorenzo, N.N., Guiraudie-Capraz, G., \& Amalric, M. (2017) Changes in SK channel expression in the basal ganglia after partial nigrostriatal dopamine lesions in rats: Functional consequences. Neuropharmacology, 113, 519-532.

Müller, M.L.T.M. \& Bohnen, N.I. (2013) Cholinergic dysfunction in Parkinson's disease. Curr Neurol Neurosci Rep, 13, 377.

Newman, L.A. \& Gold, P.E. (2016) Attenuation in rats of impairments of memory by scopolamine, a muscarinic receptor antagonist, by mecamylamine, a nicotinic receptor antagonist. Psychopharmacology (Berl), 233, 925-932.

Obeso, J.A., Rodríguez-Oroz, M.C., Rodríguez, M., Lanciego, J.L., Artieda, J., Gonzalo, N., \& Olanow, C.W. (2000) Pathophysiology of the basal ganglia in Parkinson's disease. Trends Neurosci, 23, S8-S19.

Okada, K., Nishizawa, K., Fukabori, R., Kai, N., Shiota, A., Ueda, M., Tsutsui, Y., Sakata, S., Matsushita, N., \& Kobayashi, K. (2014) Enhanced flexibility of place discrimination learning by targeting striatal cholinergic interneurons. Nature Communications, 5, 1-13.

Owen, A.M., Roberts, A.C., Hodges, J.R., Summers, B.A., Polkey, C.E., \& Robbins, T.W. (1993) Contrasting mechanisms of impaired attentional set-shifting in patients with frontal lobe damage or Parkinson's disease. Brain, 116 ( Pt 5), 1159-1175.

Pahapill, P.A. \& Lozano, A.M. (2000) The pedunculopontine nucleus and Parkinson's disease. Brain, 123, 1767-1783.

Parker, P.R.L., Lalive, A.L., \& Kreitzer, A.C. (2016) Pathway-Specific Remodeling of 
Thalamostriatal Synapses in Parkinsonian Mice. Neuron, 89, 734-740.

Paxinos, G. \& Franklin, K.B.J. (2001) The Mouse Brain in Stereotaxic Coordinates, Second Edition. edn. Academic Press, San Diego.

Pisani, A., Bernardi, G., Ding, J.J., \& Surmeier, D.J. (2007) Re-emergence of striatal cholinergic interneurons in movement disorders. Trends Neurosci, 30, 545-553.

Ragozzino, M.E. (2003) Acetylcholine actions in the dorsomedial striatum support the flexible shifting of response patterns. Neurobiol Learn Mem, 80, 257-267.

Remy, P., Doder, M., Lees, A.J., Turjanski, N., \& Brooks, D. (2005) Depression in Parkinson's disease: loss of dopamine and noradrenaline innervation in the limbic system. Brain, 128, 1314-1322.

Scarr, E. (2013) Cholinergic connectivity: it's implications for psychiatric disorders 1-26.

Scatton, B., Javoy-Agid, F., Rouquier, L., Dubois, B., \& Agid, Y.A. (1983) Reduction of cortical dopamine, noradrenaline, serotonin and their metabolites in Parkinson's disease. Brain Res, 275, 321-328.

Shen, W., Plotkin, J.L., Francardo, V., Ko, W.K.D., Xie, Z., Li, Q., Fieblinger, T., Wess, J.J., Neubig, R.R., Lindsley, C.W., Conn, P.J., Greengard, P., Bezard, E., Cenci, M.A., \& Surmeier, D.J. (2015) M4 Muscarinic Receptor Signaling Ameliorates Striatal Plasticity Deficits in Models of L-DOPA-Induced Dyskinesia. Neuron, 88, 762-773.

Threlfell, S. \& Cragg, S.J. (2011) Dopamine signaling in dorsal versus ventral striatum: the dynamic role of cholinergic interneurons. Front Syst Neurosci, 5, 11.

Threlfell, S., Lalic, T., Platt, N.J., Jennings, K.A., Deisseroth, K., \& Cragg, S.J. (2012) Striatal dopamine release is triggered by synchronized activity in cholinergic interneurons. Neuron, 75, 58-64.

Tozzi, A., de Iure, A., Bagetta, V., Tantucci, M., Durante, V., Quiroga-Varela, A., Costa, C., Di Filippo, M., Ghiglieri, V., Latagliata, E.C., Wegrzynowicz, M., Decressac, M., 
Giampà, C., Dalley, J.W., Xia, J., Gardoni, F., Mellone, M., El-Agnaf, O.M., Ardah, M.T., Puglisi-Allegra, S., Björklund, A., Spillantini, M.G., Picconi, B., \& Calabresi, P. (2016) Alpha-Synuclein Produces Early Behavioral Alterations via Striatal Cholinergic Synaptic Dysfunction by Interacting With GluN2D N-Methyl-D-Aspartate Receptor Subunit. Biol. Psychiatry, 79, 402-414.

Tzavos, A., Jih, J., \& Ragozzino, M.E. (2004) Differential effects of M1 muscarinic receptor blockade and nicotinic receptor blockade in the dorsomedial striatum on response reversal learning. Behav. Brain Res, 154, 245-253.

Vandecasteele, M., Varga, V., Berenyi, A., Papp, E., Barthó, P., Venance, L., Freund, T.F., \& Buzsáki, G. (2014) Optogenetic activation of septal cholinergic neurons suppresses sharp wave ripples and enhances theta oscillations in the hippocampus. Proc. Natl. Acad. Sci. U.S.A, 111, 13535-13540.

Volpicelli, L.A. \& Levey, A.I. (2004) Muscarinic acetylcholine receptor subtypes in cerebral cortex and hippocampus. Prog. Brain Res, 145, 59-66.

Wess, J.J., Eglen, R.M., \& Gautam, D. (2007) Muscarinic acetylcholine receptors: mutant mice provide new insights for drug development. Nat Rev Drug Discov, 6, 721-733.

Wible, C.G., Shiber, J.R., \& Olton, D.S. (1992) Hippocampus, fimbria-fornix, amygdala, and memory: Object discriminations in rats. Behav. Neurosci, 106, 751-761.

Yizhar, O., Fenno, L.E., Davidson, T.J., Mogri, M., \& Deisseroth, K. (2011) Optogenetics in neural systems. Neuron, 71, 9-34.

Zhou, F.-M., Wilson, C., \& Dani, J.A. (2003) Muscarinic and nicotinic cholinergic mechanisms in the mesostriatal dopamine systems. Neuroscientist, 9, 23-36.

Ztaou, S., Maurice, N., Camon, J., Guiraudie-Capraz, G., Kerkerian-Le Goff, L., Beurrier, C., Liberge, M., \& Amalric, M. (2016) Involvement of Striatal Cholinergic Interneurons and M1 and M4 Muscarinic Receptors in Motor Symptoms of Parkinson's Disease. J 
Page 41 of 51

Neurosci, 36, 9161-9172. 
A

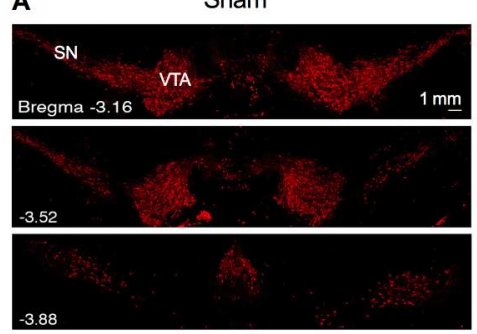

B
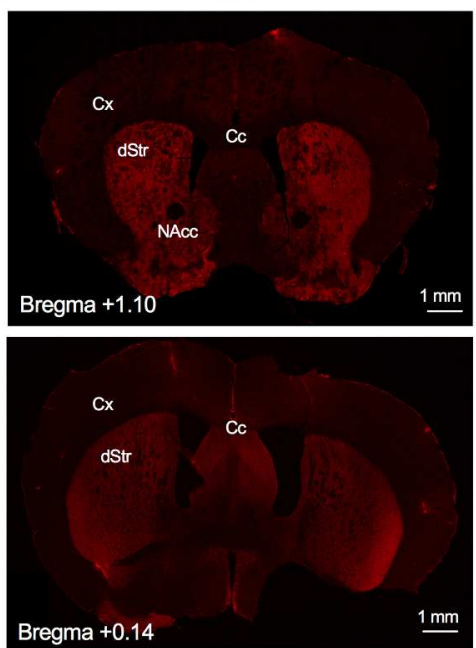

C Substantia nigra

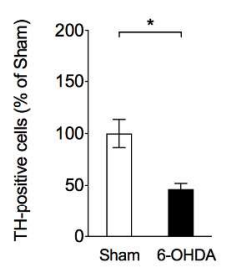

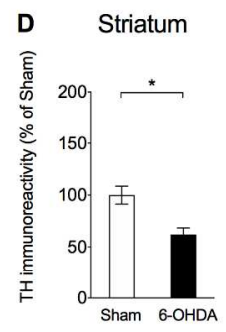

6-OHDA

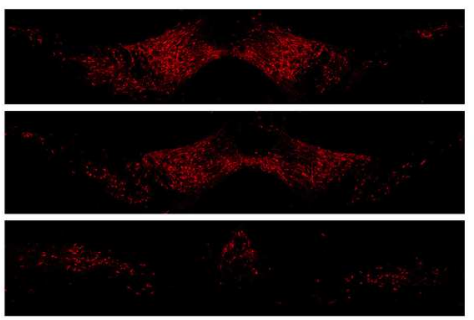

6-OHDA
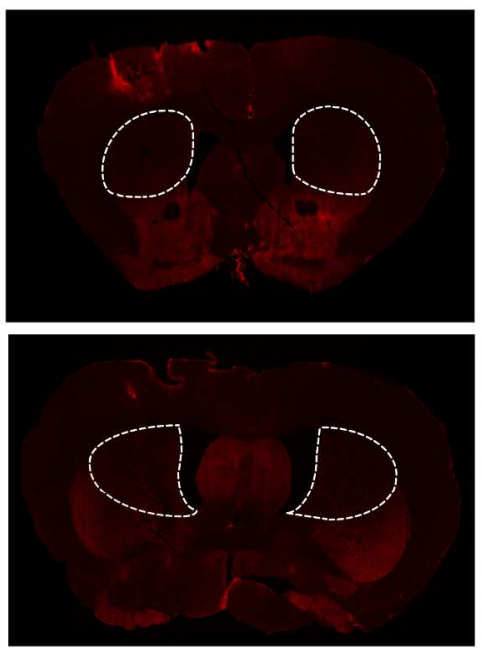

E

Correlation

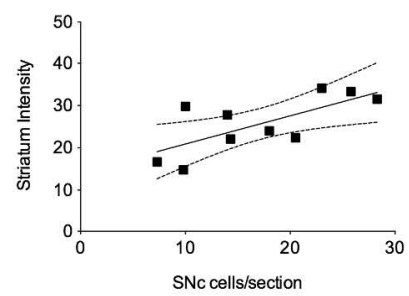

Figure 1

Figure 1. Extension of dopaminergic lesions after bilateral 6-hydroxydopamine (6-OHDA) injections in the striatum.

A. Immunofluorescence images showing TH-positive cells in the substantia nigra (SN) and the ventral tegmental area (VTA) of representative mice of sham (left) and 6-OHDA (right) groups. Scale bar: $1 \mathrm{~mm}$. B. Loss of TH immunoreactivity in the dorsal striatum at two anteriority levels in controls (Sham, left) or after bilateral 6-OHDA lesions (6-OHDA, right). Dotted lines delineates the extension of the TH immunoreactivity in the striatum. Cx, Cortex; Cc, corpus callosum; dStr: dorsal Striatum; NAcc: Nucleus accumbens. Scale bar: $1 \mathrm{~mm}$.

C-D. Quantification of TH immunoreactivity the striatum (C) and TH-positive cells in the SNC (D) in sham (n $=10)$ and $6-\mathrm{OHDA}(\mathrm{n}=12)$ mice. Data are expressed as percentage of sham and shown as mean \pm SEM. Student's t test: $* \mathrm{P}<0.01$ versus sham group.

E. Correlation between TH immunoreactivity in the striatum and TH-positive cells in the substantia nigra pars compacta $(\mathrm{SNc})$. Statistical analysis reveals a correlation between the loss of $\mathrm{TH}+$ cells and the 
decrease of TH immunoreactivity in the striatum (Pearson's $r=0.7101, P=0.0214$ ).

$184 \times 265 \mathrm{~mm}(300 \times 300$ DPI $)$ 

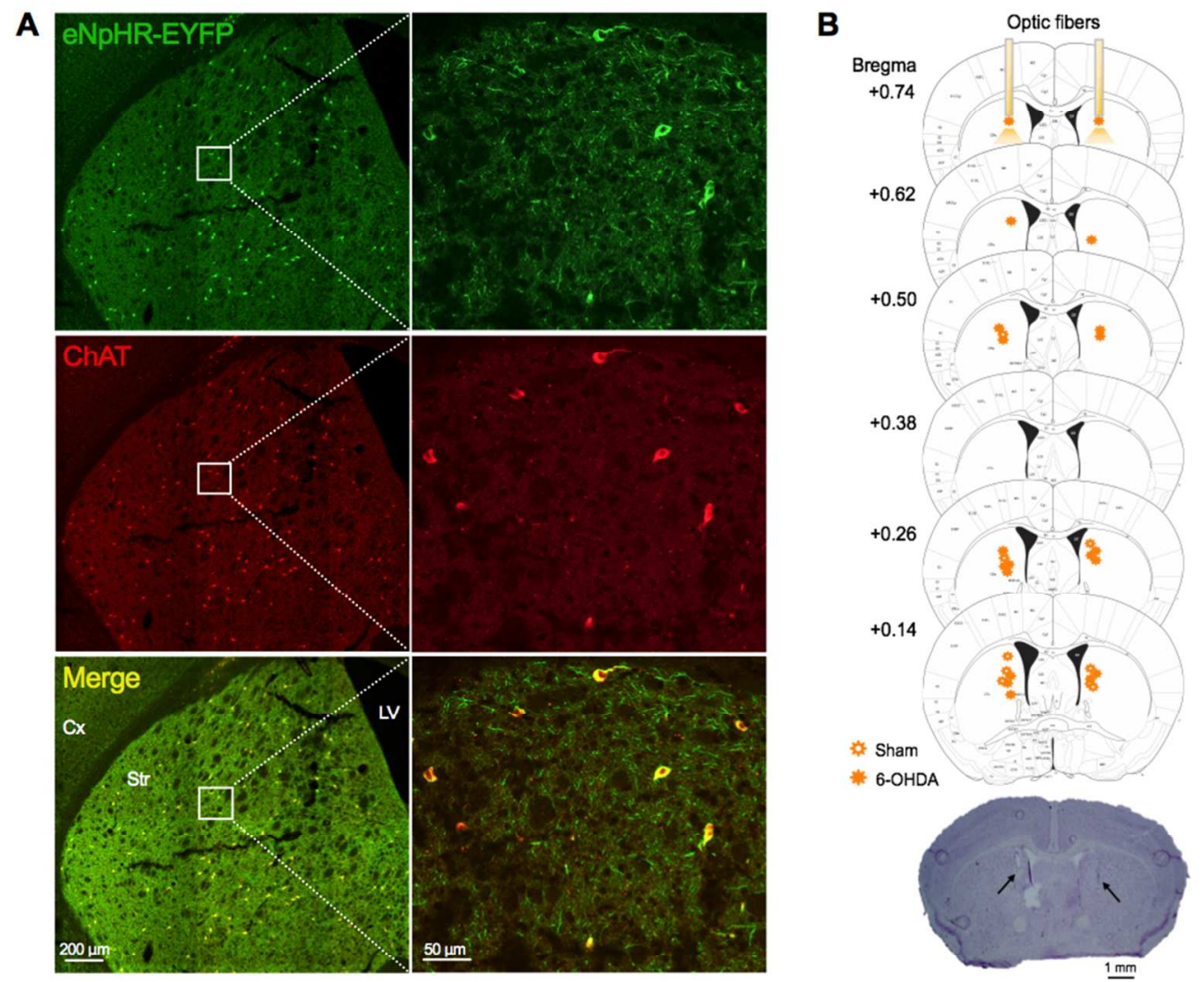

Figure 2

Figure 2. Expression of halorhodopsin (eNpHR) in cholinergic interneurons (ChIs) of the dorsal striatum and location of optic fibers in the striatum.

A. Co-expression of eNpHR in ChAT-expressing neurons, identified as ChIs, in the striatum of eNpHR transgenic mice at different enlargements. Left, scale bar: $200 \mu \mathrm{m}$, right, enlargement of indicated squares, scale bar: $50 \mu \mathrm{m}$. Cx: cortex, Str: striatum, LV: lateral ventricle.

B. Schematic reconstruction of the optical illumination sites in sham $(n=6)$ and 6-OHDA $(n=12)$ mice in the dorsal striatum at different anteriority levels, from +0.74 to $+0.14 \mathrm{~mm}$ related to bregma. Below:

Example of Nissl cresyl violet staining showing the trace of optic fibers implantation in the medial striatum. Scale bar: $1 \mathrm{~mm}$. 
A-Elevated plus maze
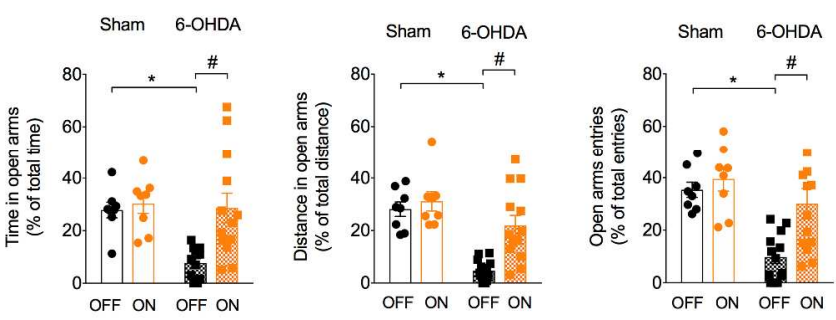

B-Social interaction
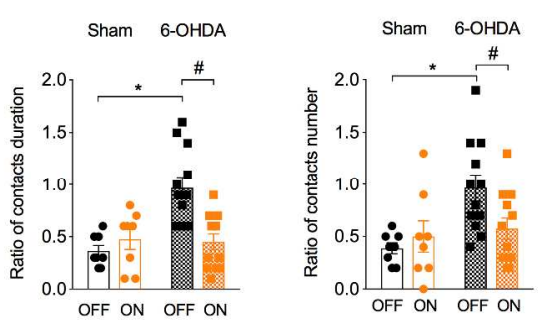

C-Spatial object recognitition
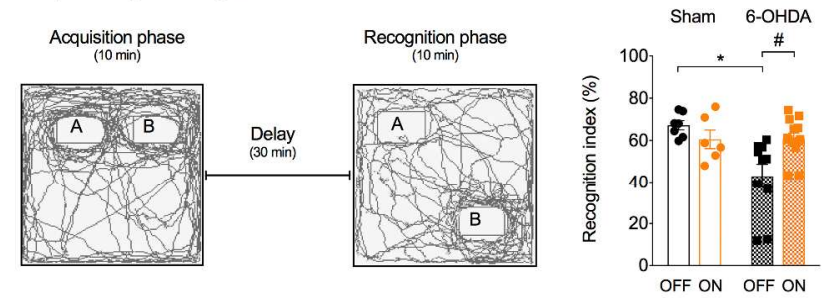

D - Non-spatial object recognitition
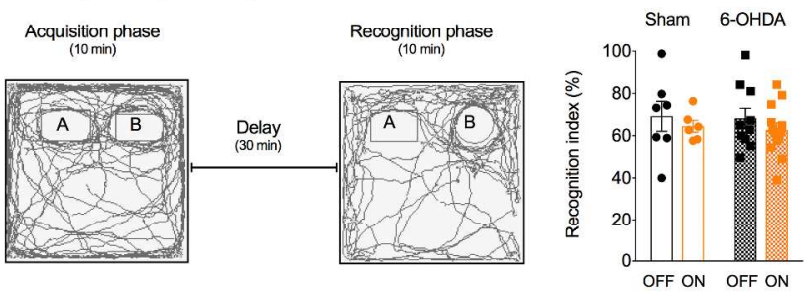

Sham : Laser OFF $O$ Laser ON

6-OHDA:

Laser OFF Laser ON

Figure 3

Figure 3. Effect of photoinhibition of striatal ChIs activity on emotional and memory dysfunction in 6-OHDAlesioned mice.

Effects of photoinhibition of striatal ChIs in the elevated plus maze (A), social interaction (B), spatial object recognition (C) and non-spatial object recognition (D) tasks. Each dot represents the individual value of one single mouse.

A. Percentage of time spent, distance traveled and number of entries in open arms in the elevated plus maze. Sham $(n=8)$ and 6-OHDA $(n=13)$ groups performed the test under two conditions: laser OFF and laser ON. Values are shown as mean \pm SEM. Bonferroni's test after significant two-way repeated-measures ANOVA: *P $<0.01$ versus sham-laser OFF; \#P $<0.01$ in comparison between laser ON and OFF.

B. Left: Representative paths of sham mice showing an active recognition of the juvenile mouse. Right: Ratio comparing the duration of contacts (in sec) and number of contacts during the second presentation (P2) to the first presentation (P1) of a same juvenile, for sham $(n=8)$ and 6-OHDA $(n=12)$ group, under two conditions: laser OFF and laser ON. Values are shown as mean \pm SEM. Bonferroni's test after significant 
two-way repeated-measures ANOVA: *P $<0.01$ versus sham-laser OFF; \#P $<0.05$ in comparison between laser ON and OFF.

C-D. Left: Representative paths of sham mice showing an active recognition during the spatial object recognition (C) and non-spatial object recognition (D) tasks. Right: Recognition index for the spatial (C) and non-spatial (D) object recognition version of the task measured in the four groups: sham-laser OFF ( $n=7$ ), sham-laser ON $(n=6), 6$-OHDA-laser OFF $(n=10)$ and 6-OHDA-laser ON $(n=13)$. Data are reported as mean \pm SEM. Bonferroni's test after significant two-way ANOVA: *P $<0.01$ versus sham-laser OFF; \#P $<0.01$ in comparison between laser ON and OFF.

$184 \times 334 \mathrm{~mm}(300 \times 300$ DPI $)$ 
A - Elevated plus maze
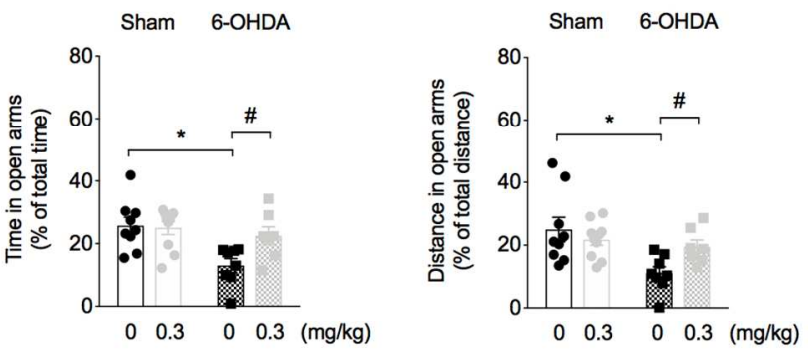

B - Social interaction
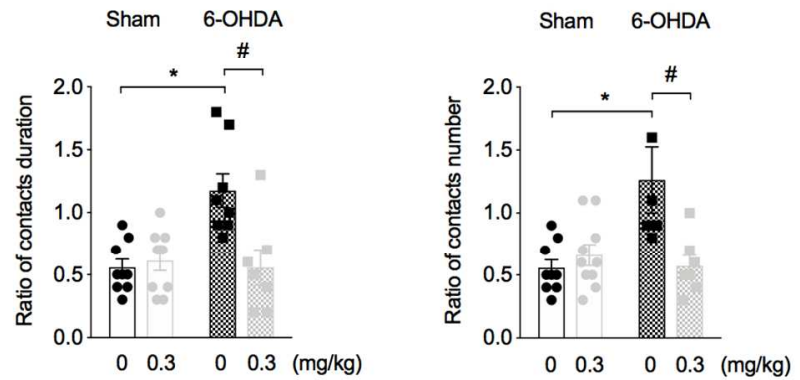

C-Spatial object recognitition

D - Non-spatial object recognitition
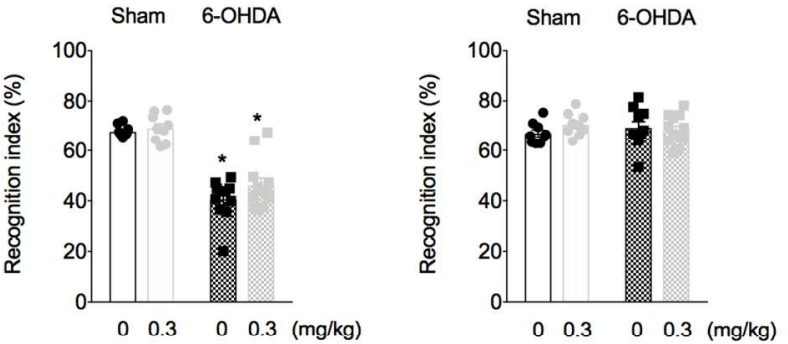

Sham :

Vehicle Telenzepine

6-OHDA:

Vehicle Telenzepine

Figure 4

Figure 4. Effects of M1 mAChR antagonist systemic injection on anxiety-like behavior and cognitive deficits in 6-OHDA-lesioned mice.

Effects of the M1 mAChR antagonist telenzepine, injected i.p. at a dose of $0.3 \mathrm{mg} / \mathrm{kg}$, in the elevated plus maze (A), social interaction (B), spatial object recognition (C) and non-spatial object recognition (D) tasks. Each dot represents the individual value of one single mouse.

A. Percentage of time spent, distance traveled and number of entries in open arms in the elevated plus maze measured in one cohort divided in four groups: sham-vehicle $(n=9)$, sham-telenzepine $(n=10), 6$ OHDA-vehicle $(n=8)$ and 6-OHDA-telenzepine $(n=7)$. Values are shown as mean \pm SEM. Bonferroni's test after significant two-way repeated-measures ANOVA: *P $<0.01$ versus sham-vehicle group; \#P $<0.05$ in comparison between telenzepine and vehicle.

B. Ratio comparing the duration of contacts (in sec) (left) and number of contacts (right) during the second presentation (P2) to the first presentation (P1) of a same juvenile, in the same cohort than the elevated plus maze experiment. Values are shown as mean \pm SEM. Bonferroni's test after significant two-way repeated- 
measures ANOVA: *P $<0.01$ versus sham-vehicle; \#P $<0.01$ in comparison between telenzepine and vehicle.

C-D. Recognition index for the spatial displacement of the object (C) and non-spatial novel object recognition (D) in a second cohort divided in four groups: sham-vehicle $(n=9-10)$, sham-telenzepine ( $n=$ 9), 6-OHDA-vehicle $(n=10-11)$ and 6-OHDA-telenzepine $(n=12)$. Data are reported as mean \pm SEM. Bonferroni's test after significant two-way ANOVA: $* P<0.01$ versus sham-vehicle group.

$88 \times 150 \mathrm{~mm}(300 \times 300 \mathrm{DPI})$ 
Table 1

\begin{tabular}{|c|c|c|c|c|}
\hline & \multicolumn{2}{|c|}{ Sham } & \multicolumn{2}{|c|}{ 6-OHDA } \\
\hline & Vehicle & Treatment & Vehicle & Treatment \\
\hline \multicolumn{5}{|l|}{ Photoinhibition } \\
\hline Elevated plus maze ${ }^{a}$ & $6924.5 \pm 680.5$ & $7474.9 \pm 727.7$ & $6656.1 \pm 543.0$ & $5611.1 \pm 645.4$ \\
\hline \multirow[t]{2}{*}{ Social interaction ${ }^{\mathrm{b}}$} & $2070.6 \pm 280.0(\mathrm{P} 1)$ & $2058.2 \pm 200.8(P 1)$ & $1687.7 \pm 150.2(\mathrm{P} 1)$ & $1807.0 \pm 144.2(\mathrm{P} 1)$ \\
\hline & $1814.0 \pm 130.7(\mathrm{P} 2)$ & $2295.8 \pm 215.3(\mathrm{P} 2)$ & $1839.2 \pm 202.3(\mathrm{P} 2)$ & $1811.2 \pm 227.5(\mathrm{P} 2)$ \\
\hline Spatial object recognitionc ${ }^{c}$ & $4331.1 \pm 482.8$ & $3828.2 \pm 342.3$ & $3623.8 \pm 333.8$ & $4715 \pm 509.7$ \\
\hline Non-spatial object recognitiond & $3451.6 \pm 376.8$ & $3506.9 \pm 368.2$ & $3145.2 \pm 313.8$ & $3707.3 \pm 228.7$ \\
\hline \multicolumn{5}{|l|}{ Telenzepine } \\
\hline Elevated plus maze & $8119.9 \pm 414.5$ & $7943.0 \pm 422.2$ & $7288.5 \pm 498.5$ & $6625.4 \pm 851.0$ \\
\hline \multirow[t]{2}{*}{ Social interaction ${ }^{\dagger}$} & $2063.9 \pm 192.4(\mathrm{P} 1)$ & $1807.7 \pm 69.3(\mathrm{P} 1)$ & $1779.5 \pm 65.7(\mathrm{P} 1)$ & $1841.2 \pm 134.8(\mathrm{P} 1)$ \\
\hline & $2107.2 \pm 179.9(\mathrm{P} 2)$ & $1828.7 \pm 73.6(\mathrm{P} 2)$ & $1868.7 \pm 83.7(\mathrm{P} 2)$ & $1798.1 \pm 109.6(\mathrm{P} 2)$ \\
\hline Spatial object recognitiong & $4872.1 \pm 272.8$ & $4942.2 \pm 329.9$ & $4129.4 \pm 312.6$ & $3731.5 \pm 298.5$ \\
\hline Non-spatial object recognition h & $4299.8 \pm 268.7$ & $4386.2 \pm 244.6$ & $3562.5 \pm 316.2$ & $3749.7 \pm 215.3$ \\
\hline
\end{tabular}

Table 1. Locomotor activity measured in emotional and cognitive tests after striatal cholinergic interneurons photoinhibition or M1 muscarinic cholinergic receptor blockade with telenzepine ( $3 \mathrm{mg} / \mathrm{kg}$ i.p.).

Global locomotor activity represents the total distance covered in each apparatus measured in $\mathrm{cm}$ (mean \pm SEM) during the testing period of the elevated plus maze, social interaction, spatial and non-spatial object recognition experiments. Two-way ANOVA with groups (6-OHDA versus sham) as between factor and pharmacological treatment (treatment versus vehicle) as within factor showed no significant difference of global locomotor activity in the maze or open field.

ANOVA, analysis of variance; 6-OHDA, 6-hydroxydopamine; P1, first presentation; P2, second presentation.

${ }^{\mathrm{a}} F_{1,19}=2.47, P=0.13 ;{ }^{\mathrm{b}} F_{3,36}=0.48, P=0.39 ;{ }^{\mathrm{c}} F_{1,32}=2.61, P=0.11 ;{ }^{\mathrm{d}} F_{1,32}=0.62, P=0.43 ;{ }^{\mathrm{e}} F_{1,30}=0.20, P=0.66 ;{ }^{\mathrm{f}} F_{3,30}=0.29, P=0.84 ;{ }^{\mathrm{g}} F_{1,38}$ $=0.58, P=0.45 ;{ }^{\mathrm{h}} F_{1,36}=0.04, P=0.85$. 


\section{Normal}

Chls photoinhibition

- Anxiety-like behaviour

- Social short-term memory

- Spatial short-term memory

M1 antagonist

- Anxiety-like behaviour

- Social short-term memory
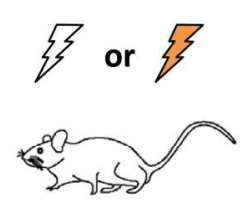

or

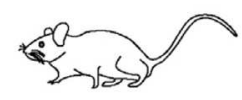

\section{Parkinsonian state}
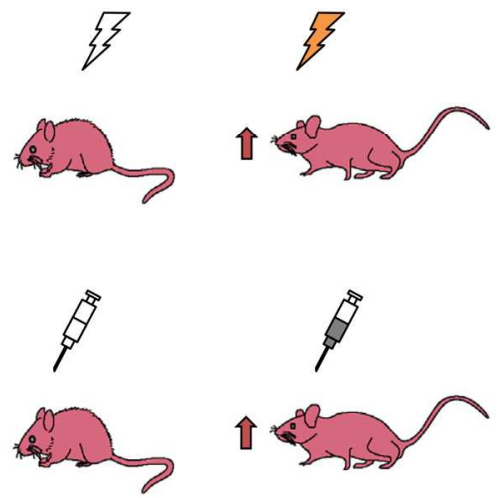

$190 \times 91 \mathrm{~mm}(300 \times 300 \mathrm{DPI})$ 
Graphical abstract text :

Optogenetic photoinhibition of striatal cholinergic interneurons (Chls) reduced anxiety-like behaviour and reversed social memory recognition of a congener and visuospatial object recognition in mice with moderate nigrostriatal dopamine lesions, a model of prodromal phase of Parkinson's disease (PD).

Telenzepine $(0.3 \mathrm{mg} / \mathrm{kg})$, a preferential M1 muscarinic cholinergic receptors antagonist, improved anxiety-like behaviour, social memory recognition but not spatial memory deficits.

Striatal Chls could contribute to cognitive and anxiety symptoms in a partial dopamine depletion mice model of early PD, when motor symptoms are not manifest. M1 muscarinic receptor antagonists may represent a possible therapeutic target, among others, to counteract these symptoms. 